OPEN ACCESS

Edited by:

David Olagnier,

Aarhus University, Denmark

Reviewed by:

Geneviève Pépin,

Université du Québec à Trois-Rivières,

Canada

Claire Isabelle Vanpouille-Box, Weill Cornell Medicine, United States

*Correspondence:

Julie Constanzo

julie.constanzo@inserm.fr

${ }^{\dagger}$ These authors have contributed equally to this work

Specialty section: This article was submitted to Inflammation,

a section of the journal

Frontiers in Immunology

Received: 14 March 2021 Accepted: 26 April 2021

Published: 17 May 2021

Citation:

Constanzo J, Faget J, Ursino C, Badie C and Pouget J-P (2021)

Radiation-Induced Immunity and

Toxicities: The Versatility

of the CGAS-STING Pathway.

Front. Immunol. 12:680503. doi: 10.3389/fimmu.2021.680503

\section{Radiation-Induced Immunity and Toxicities: The Versatility of the cGAS-STING Pathway}

\author{
Julie Constanzo ${ }^{1 *}$, Julien Faget ${ }^{1 \dagger}$, Chiara Ursino ${ }^{1}$, Christophe Badie ${ }^{2}$ \\ and Jean-Pierre Pouget ${ }^{1}$
}

1 IRCM, Institut de Recherche en Cancérologie de Montpellier, INSERM U1194, Université de Montpellier, Institut régional du Cancer de Montpellier, Montpellier, France, ${ }^{2}$ Cancer Mechanisms and Biomarkers Group, Radiation Effects Department, Centre for Radiation, Chemical \& Environmental Hazards Public Health England Chilton, Didcot, United Kingdom

In the past decade, radiation therapy (RT) entered the era of personalized medicine, following the striking improvements in radiation delivery and treatment planning optimization, and in the understanding of the cancer response, including the immunological response. The next challenge is to identify the optimal radiation regimen(s) to induce a clinically relevant anti-tumor immunity response. Organs at risks and the tumor microenvironment (e.g. endothelial cells, macrophages and fibroblasts) often limit the radiation regimen effects due to adverse toxicities. Here, we reviewed how RT can modulate the immune response involved in the tumor control and side effects associated with inflammatory processes. Moreover, we discussed the versatile roles of tumor microenvironment components during RT, how the innate immune sensing of RTinduced genotoxicity, through the cGAS-STING pathway, might link the anti-tumor immune response, radiation-induced necrosis and radiation-induced fibrosis, and how a better understanding of the switch between favorable and deleterious events might help to define innovative approaches to increase RT benefits in patients with cancer.

Keywords: radiation, radiotherapy, targeted radionuclide therapy, inflammation, nucleic acids, bystander immunity, cGAS, STING

\section{INTRODUCTION}

In one century, radiation therapy (RT) has become a cornerstone of cancer treatment and is proposed in about $50 \%$ of therapeutic schedules. RT goal is to deliver high amounts of energy in cancer cells that will produce unrepairable damage leading to cell death. However, already the first studies on RT reported that healthy tissues, such as skin, are limiting organs showing specific side effects (for instance, erythema and telangiectasia for skin). The amount of energy delivered to tissues was identified as the critical parameter of RT, and the radiation dose in gray units (Gy) was defined for treatment rationalization. It was also observed that tumors and healthy tissues respond differently when the radiation dose is fractionated. Until the 1940s, various dose and dose per fraction were systemically tested to improve RT efficacy and to better protect skin from early and late reactions (1). This led to the standard therapeutic schedule used today: 2 Gy per fraction, 5 fractions per week, and 6-8 weeks of overall treatment time (2). This has been accompanied 
by improvements in radiation delivery to the tumor, and the current image-guided radiotherapy systems provide high ballistic precision.

These advances have comforted the target cell theory according to which only tumor cells crossed by radiation will die, ultimately leading to eradication of clonogenic tumor cells and to tumor control. However, exposure of healthy tissues remains a matter of concern (3). Specifically, it has been observed that the response to RT is not the same in all patients, and late radiation toxicities, such as radiation-induced necrosis [RN $(4,5)]$ and fibrosis (RIF) (6-8), have been described. Besides the intrinsic patient radiosensitivity, total dose, dose per fraction, irradiated volume, and treatment combinations (e.g. endocrine therapy, chemotherapy, history of surgery) $(9,10)$ could be involved in such side effects.

A new paradigm was established in the 1950s when a possible role for RT-enhanced immune response against cancer cells was suggested. Regression of cancer cells at a distance from the radiation field was reported, leading to the introduction of the abscopal effect concept (11). These observations that challenge the target cell theory have been supported by many other studies (12-15), and the immune response role during RT is today strengthened by the benefit observed when combining RT and immunotherapy, which stimulates or suppresses the immune system to help the body fight cancer (e.g. monoclonal antibodies) $(14,16,17)$.

Here, we will review how RT modulates the immune response towards a better tumor control or side effects associated with inflammatory processes. After briefly describing the cellular and tissue responses to RT and the different RT modalities, we will discuss how the innate immune sensing of RT-induced genotoxicity might link anti-tumor immune response, RN and RIF, and how a better understanding of the switch between favorable and deleterious events might help to define innovative approaches to increase RT benefit in patients with cancer.

\section{Cellular and Tissue Responses to RT}

$\mathrm{RT}$ is based on the principle that radiation will produce lethal lesions in exposed cells. This starts with the ionization and excitation of molecules contained in cells, leading to the production of radical species, such as reactive oxygen (ROS) and nitrogen species (NOS) that will damage cell constituents. These damages may be repaired (cells will survive), misrepaired (cells undergo abnormal proliferation), or not repairable (cells will die). Among all the radiation-sensitive targets, nuclear DNA has been the most investigated. Indeed, survival of irradiated cells is closely related to the level of unrepaired DNA double-strand breaks, and the DNA damage response (DDR) plays a major role in the final cellular outcome. Other subcellular targets, such as cell membrane (18-20), mitochondria $(21,22)$ and lysosomes, also may contribute to the final outcome. It must be noted that cell killing will be more important when the dose and dose-rate increase than when the dose is fractionated or delivered at low dose-rate.

Target cell death upon RT leads to reduction in tissue function (1). As RT delivers high fractionated dose (2 Gy per fraction, 5 fractions per week, total dose between 40 and 70 Gy), the priority is to precisely control the exposure to radiation of tumor cells and healthy tissues. The determinist effects, occurring beyond a certain dose-threshold ( $>0.5 \mathrm{~Gy}$ ), are proportional to the dose, according to a $S$ shape curve (sigmoid curve), before reaching a plateau at high dose. Therefore, by controlling the dose, it is possible to predict the biological effect, e.g. the tumor control probability. The S curve obtained for healthy tissues (normal tissue complications probability) is quite similar as the one obtained for tumor cells, but the dose threshold is higher. This indicates that the tumor is more sensitive to radiation than healthy tissues when using the previously described fractionated schedule. Therefore, it is possible to define a therapeutic window where tumor growth can be controlled with acceptable side effects. The organs concerned by deterministic effects usually display high proliferation rates (i.e. tumor, skin, bone marrow, digestive tract), but other organs also may be concerned, for instance the nervous system.

\section{RT Modalities and Differential Effects on Tissues}

It took more than 50 years of preclinical and clinical data to define the current standard therapeutic schedule of RT. This schedule allows controlling the tumor, while minimizing side effects. At the beginning of RT, the first systems produced low energy X-rays that delivered huge doses to the skin, which was used as the guide for therapeutic schedules. Schedules were progressively improved to deliver the maximum dose not to the skin but to the tumor. This was the beginning of a huge progress in the design/development of technological devices with the final goal of increasing the ballistic accuracy and improving the ratio between disease control and toxicity (23). Threedimensional conformal radiation therapy (3D-CRT), intensitymodulated radiation therapy (IMRT), stereotactic body radiation therapy (SBRT/SABR) and stereotactic radiation surgery (SRS), proton therapy (and to a lesser extent hadrontherapy with heavy ions) (24), and more recently FLASH RT (25) have progressively been implemented. For example, 3D-CRT aims at delivering radiation to the gross tumor volume with a margin for microscopic tumor extension and a further margin uncertainties for organ in motion, while IMRT allows the oncologist create irregular-shaped radiation doses that conform to the tumor whilst avoiding critical organs. For instance, the optimal radiation technique to treat breast cancer may vary with patient anatomy and laterality of the breast cancer. IMRT provide better conformality of the high dose to the target regions than conventional 3D-CRT, but at the expense of more tissue (contralateral breast and lung) exposed to low radiation doses. Also, due to physical properties, proton therapy improves target coverage and conformality with a high dose volume to the target, and significantly reduces both organs at risks and integral doses. Thus, the more the radiation technique allows a perfect coverage of the tumor shape while avoiding healthy surrounding tissues, the more the dose can be increased (improving the cytotoxic effect of the physical dose), intensificated, or hypofractionated to further improving outcomes. 
However, some of conventional RT modalities are not always suitable for the treatment of disseminated or diffuse disease or of tumors located very close to organs at risk because it would lead to an unacceptable exposure of healthy tissues to high radiation doses. Very early, clinical radionuclides were identified as an alternative to RT because they emit radiation and can be used as unsealed sources for intravenous injection. In 1941, iodine 131 (26), which is taken up by the thyroid gland, was the first tested radionuclide for hyperthyroidism treatment, marking the birth of nuclear medicine (27). Recently, Xofigo ${ }^{\mathrm{TM}}\left({ }^{223} \mathrm{RaCl}_{2}\right)$ has been approved for bone metastasis management in patients with prostate cancer (28). In brachytherapy (also called Curietherapy), radionuclides are locked in a sealed capsule placed close to the tumor (e.g. prostate cancer), and then the radiations cross the capsule and irradiate the localized tumor. In 1951, for the first time, radionuclides were radiolabeled with vehicles, such as monoclonal antibodies against cancer cells (29$31)$ and later peptides. For instance, Lutathera ${ }^{\mathrm{TM}}\left({ }^{177} \mathrm{Lu}-\right.$ DOTATATE) has been approved for treating neuroendocrine tumors (32-34). However, radionuclide therapy also is associated with side effects due to exposure of healthy tissues. For example, treatment with Lutathera ${ }^{\mathrm{TM}}$ strongly increases progression-free survival in patients (32), but whole blood and bone marrow are inevitably exposed to radiation that may lead to long-term toxicities. Subacute hematologic toxicity (grade 3/4) after Lutathera $^{\mathrm{TM}}$ has been observed in $11 \%$ of patients (35), and long-term safety concerns include myelodysplastic syndrome (MDS) and leukemia $(32,36)$.

The choice between the different RT modalities depends on the tumor type and its localization. The chosen modality will influence the delivered dose and dose-rate and the nature of the lesions produced in cells. For example SBRT and SRS, which deliver high individual radiation doses with enhanced precision accuracy in only few treatment fractions, can be used to ablate small and well-defined primary tumors anywhere in the body, such as non-small cell lung cancer (NSCLC) (37-39), or brain metastases (SRS) $(40,41)$. However, these modalities may cause late RIF and RN. RN is a well-characterized effect of SRS and is occasionally associated with serious neurologic sequelae (42). A preclinical study in normal rats whose brain was exposed to a single radiation dose (37 Gy at 30\% using a Gamma Knife ${ }^{\odot}$ device) found vascular disorders and neovascularization (43) with no detectable behavior changes at day 54 post-irradiation. At day 110, rats exhibited large $\mathrm{RN}$ surrounded by an increasing gradient (distal to proximal from the $\mathrm{RN}$ ) of microglia that accumulated near newly sprouted blood vessels, upregulation of $\mathrm{Iba}^{+} \mathrm{CD}^{+} 8^{+}$macrophages, and infiltrating $\mathrm{CD} 3^{+}$ $\mathrm{T}$ cells (44). These effects were accompanied by irreversible neuroinflammation, memory loss and a decrease in anxietylike behavior (44). In the context of brain RN pathophysiology, there are two main theories whether it is likely that the true cause is multifactorial: i) the vascular injury theory and ii) the glial cell theory. In the first case scenario, radiation disrupts the bloodbrain barrier, resulting in increased capillary leakiness and vascular permeability. Radiation, especially in large fraction sizes $>8 \mathrm{~Gy}$, activates acid sphingomyelinase and causes upregulation of ceramide, which in turn causes endothelial apoptosis $(20,45)$. This leads to increased oxygen-free radicals, a pro-inflammatory milieu (through release of tumor-necrosis factor and interleukin-1 $\beta$ ) (46), and amongst other increased production of vascular-endothelial growth factor (VEGF). This cascade leads to anarchic vessel sprouting resulting in ischemia and cell death (47). In the second case, radiation can also damage glial cells. Damage to oligodendrocytes and their progenitors result in demyelination (48), accompanied by leaky capillaries, which result in perilesional edema $(43,48)$. Therefore, it is important to understand the balance between beneficial and deleterious effects of the radiation-induced inflammatory response, and how exposed tumor cells communicate with their microenvironment.

\section{Revisiting the Target Cell Paradigm Accounting for Non-Irradiated Bystander Cell Killing}

For about one century, RT has been considered as a ballistic therapeutic approach where radiation is seen as projectiles targeting tumor cells. Accordingly, only cells traversed by radiation will die. There is now a huge body of evidence indicating that irradiated cells communicate with nonirradiated neighboring cells, leading to the so-called bystander response to radiation that includes cytotoxic and genotoxic effects, such as chromatid exchange (49), mutagenic effects (50), micronucleus formation (51) and DNA damage-inducible protein upregulation $(52,53)$. Besides these short-distance effects, there are long-range effects that involve the immune response activation through the production/release by irradiated cells of pro-immunogenic factors, such as tumor antigens (54), Natural Killer (NK) receptor G2D (NKG2D) ligands that act as danger signals to alert NK cells (55), and through the recruitment of $\mathrm{CD}^{+} \mathrm{T}$ cells and myeloid cells (56) together with the production of type I Interferon (IFN) (57). Simultaneously, RT can lead to immunogenic death of cancer cells (15) that can subsequently favor the immune cell response toward the surveillance and eradication of transformed cells (58). Immunogenic cell death consists in the release of immunostimulatory damage-associated molecular patterns (DAMPs) by dying cells (59), for instance extracellular ATP (60), extracellular DNA (61), nuclear DNA-binding protein high mobility group box 1 (HMGB1) (62), and endoplasmic reticulum chaperones, such as calreticulin (63). Irradiated cells produce also inflammation-related cytokines (e.g. IFNs, IL-1, IL-6, IL-8, VEGF, EGFR, and TNF $\alpha$ ) encoded by "early response" genes (64) that are induced within minutes to hours following RT exposure. This is associated with ROS production and cytokine production that will participate in the creation of a DAMPassociated proinflammatory micro-environment. Mediators of systemic effects and DDR/DNA repair components interact also with components of the innate immune response, such as pattern recognition receptors, and with DNA repair proteins (BRCA1, XRCC1, DNA-dependent protein kinases, Ku70/80) (64). For instance, during RT (or chemotherapy), dendritic cells (DCs) require signaling through Toll-like receptor 4 (TLR4) for efficient 
processing and cross-presentation of antigen from dying tumor cells (releasing HMGB1). Apetoh et al. demonstrated that in vivo, local RT reduced tumor growth on CT26 colon cancers and TS/A breast carcinomas, and prolonged the survival of tumor-bearing immunocompetent wild-type mice, which was less effective in $\mathrm{Tlr}^{-/-}$and athymic nude mice (65).

\section{Critical Tissues and Cell Response to RT: Bone Marrow and Circulating Blood Cells}

Although treatment planning allows delivering most of the radiation dose to the tumor, the surrounding healthy tissues also are exposed to radiation, but at lower doses. Consequently, the surrounding tissues, including the vascular system, also are included in the exposed volume. The tumor and infiltrating immune cells (myeloid cells and lymphocytes), whose number depends on the tumor immune microenvironment (hot, cold, and immune-altered), are also irradiated. Consequently, RT can have detrimental effects on the hematological compartment. Bone marrow aplasia occurs for doses $>3$ Gy and death due to hematopoietic syndrome occurs upon whole-body exposure to doses that are expected to cause the death of $50 \%$ of exposed people (LD50 = 4.5 Gy) (66). When irradiation is not fatal, the number of hematopoietic stem cells returns progressively to normal, but this can take years. Higher intramedullary cytotoxicity due to abnormal hematopoiesis can be observed, although blood formula has returned to normal values. This might be due to RT-linked modifications of the stem cell microenvironment, niches and/or vascularization. Long term effects of irradiation of bone marrow have been reported in patients treated for ankylosing spondylitis (67) or in atomic bomb survivors. They mainly consist of acute leukemia a myelodysplasia occurring between 5 and 10 years after exposure. However their occurrence depend on the dose and have not been observed after RT alone but more after combination with chemotherapy $(68,69)$.

Bone marrow is a tissue with a hierarchical organization that is involved in the early response to RT. Quiescent or proliferating hematopoietic stem cells are located in bone marrow. Except for $\mathrm{T}$ lymphocytes that differentiate in thymus, hematopoietic cells proliferate and differentiate in the bone marrow before entering the blood circulation. During RT, a proportion of stem cells is killed and the negative effect on hematopoiesis is proportional to the irradiation dose. As blood cells have a limited lifespan, blood cell depletion will be detectable after the non-replacement of mature cells by young differentiating cells. The immune cell radiosensitivity depends on the lineage, maturity, and activation status. All bone marrow cells and particularly progenitors are sensitive to RT, and 1 Gy kills about $2 / 3$ of all progenitor cells. Conversely, mature cells, except lymphocytes, are relatively resistant to RT. Lymphocytes are particularly radiationsensitive, and a decrease in circulating lymphocytes, due to apoptosis, is observed already with $0.3 \mathrm{~Gy}$. At $1 \mathrm{~Gy}$, the decrease becomes significant and occurs within 3 days. B cells and naïve $\mathrm{T}$ helper (Th) cells are the most radiation-sensitive, whereas $\mathrm{T}$ memory cells, natural killer $\mathrm{T}$ cells, and regulatory $\mathrm{T}$ cells (Tregs) are more resistant (64).
In recent years, the transcriptional response to radiation exposure has been much studied. This is important because it has been reported that the gene expression signature of blood lymphocytes can help to predict the clinical outcome in human cancers (70). Upon exposure to RT, multiple signal transduction pathways are activated, resulting in complex alterations in gene expression in circulating immune cells [e.g. Kabacik et al. (71)]. For instance, $\mathrm{CD}^{+}$and $\mathrm{CD}^{+} \mathrm{T}$ cells produce IFN- $\gamma$, contributing to the formation of an inflammatory environment that favors the anti-tumor immunity (72). Irradiated human monocytes and macrophages activate transiently p53- and ATMdependent mechanisms. The transcriptional factors TP53 and nuclear factor kappa B (NF- $\mathrm{KB})$, which play a central in immune and inflammatory responses by regulating the expression of proinflammatory cytokines and chemokines such as TNF- $\alpha$, induce the expression of inflammatory cytokine-encoding genes, thus establishing a direct link between radiation-induced DNA damage response and radiation-induced inflammation (73).

Circulating leukocytes are only exposed when passing through exposed blood vessels and receive a much lower dose, which is difficult to calculate accurately. Yet, this is a crucial issue because the transcriptional changes observed in vitro following exposure of whole blood samples are quantitatively (74) and qualitatively (75) different in function of the dose. High doses induce mainly p53-dependent signaling, and genes involved in the stress response and apoptosis. Their level of expression is dose-dependent down to 10-50 mGy. Low doses predominantly induce the NF- $\kappa \mathrm{B}$ pathway and the regulation of genes involved, for instance, in cytosolic DNA sensing and chemokine and cytokine signaling, rather than radiation-induced direct cell killing. NF- $\kappa B, p 53$, breast cancer associated protein 1 (BRCA1) and AP-1 are among the main transcription factors activated by radiation exposure and regulated by the DDR (76), but low doses induce more immune-stimulatory responses (75). Therefore, it can be hypothesized that the dose received by immune cells and consequently the triggered responses are determined by their localization during RT. Interestingly, the influence of the tumor presence on the expression of several stress genes in circulating white blood cells has been investigated, and similar levels of expression in pre-exposure cancer samples and in normal donor samples were observed (77).

Additionally, the type of radiation (X-rays, gamma, proton, beta or alpha particles), the dose rate (around 1 Gy per minute, FLASH irradiation in seconds, or protracted - days - irradiation in targeted radiotherapy, TRT) and the RT type (e.g. IMRT or SABR), which limits the dose to the microenvironment and surrounding organs, can modify the volume of irradiated blood, the dose to circulating leukocytes and consequently the associated transcriptional modifications. This is illustrated by the different modulation of the expression of inflammation genes, such as TGF $\beta 1$ (cytokine with anti-inflammatory properties), IL-1 $\beta$ and IL-6 (pro-inflammatory), CCL3 (involved in the recruitment and activation of granulocytes) and IL8 (neutrophil recruitment), in function of the RT type (IMRT and SABR) and total dose (78). For instance, TGF $\beta$ may be a major obstacle to the optimal activation of antitumor T-cell 
responses by RT. Bouquet et al. demonstrated that TGF $\beta$ inhibition prior to radiation attenuated DNA damage responses, increased clonogenic cell death, and promoted tumor growth delay, and thus may be an effective additional therapy in cancer RT (79). Also, in preclinical models of metastatic breast cancer, Vanpouille-Box et al. showed that anti-TGF $\beta$ antibodies administered during RT uncovered the ability of RT to induce T-cell responses to endogenous tumor antigens (80). Interestingly, only the combination of RT with anti-TGF $\beta$, but not each treatment alone, induced T-cellmediated rejection of the irradiated tumor and non-irradiated metastases in mice, indicating that blocking TGF $\beta$ unleashes the potential of RT to promote an in situ tumor vaccine (80). In addition, TGF $\beta$ activation depends on radiation modalities. Vozenin's research team demonstrated that conventional RT (15 Gy) triggered lung fibrosis associated with activation of the TGF $\beta$ cascade, whereas no complications have been observed after doses of FLASH below 20 Gy for more than 36 weeks after irradiation (81).

Also, the effects of RT on suppressive immune cells, such as regulatory $\mathrm{T}$ cells (Tregs), in the tumor microenvironment (TME) are not fully elucidated. For example, across several tumor models (B16/F10, RENCA, and MC38) Muroyama et al. demonstrated that RT (10 Gy) significantly increased tumorinfiltrating Tregs compared with non-irradiated tumors. The authors found that tumor-infiltrating Tregs from irradiated tumors had equal or improved suppressive capacity compared with non-irradiated tumors, independently of TGF $\beta$ (82). Consequently, blocking Tregs infiltration in tumors might be an interesting therapeutic strategy in combination with RT and anti-PD-L1, to overcome RT-induced immunosuppressive Tregs and drive an abscopal effect (83).

In conclusion, there is a direct link between radiation-induced DNA damage-dependent changes in gene expression and radiation-induced inflammation. These changes need to be better investigated to decipher these complex interactions.

Overall, this section showed the complex interaction between ionizing radiation, tumor cells and TME. It also highlighted that not all observed effects are linked to direct radiation damage crossing cancer cells, but also to bystander and systemic effects.

\section{JANUS-FACED TUMOR MICROENVIRONMENT COMPONENTS DURING RT}

RT is detrimental for bone marrow and circulating blood cells through their direct irradiation, but it can also via its indirect effects, trigger the activation of immune cells, as observed when RT is combined with immunotherapy (84). RT physical parameters, such as dose and dose-rate, are key determinant of the response type. Nevertheless, it must be kept in mind that the immune response can participate in cancer control, but can also contribute to the deleterious inflammatory effects observed in healthy tissues. The balance between radiation-induced immunity and toxicity is influenced by the TME cell composition, architecture and intercellular communications. The role of macrophages, endothelial cells, fibroblasts and mesenchymal stem cells (MSC) in the TME is presented in the following paragraphs.

\section{Macrophages}

In macrophages, ionizing radiation induces the proinflammatory phenotype that favors their pro-invasive and pro-angiogenic functions in vitro (85). This involves the transient activation of $\mathrm{p} 53$ - and ATM-dependent responses. The transcription factors $\mathrm{p} 53$ and NF- $\mathrm{KB}$, which have key roles in the immune and inflammatory responses, regulate the expression of pro-inflammatory cytokines and chemokines, such as TNF- $\alpha$, and lead to the expression of inflammatory cytokine-encoding genes, thus establishing a direct link between radiation-induced DDR and radiation-induced inflammation (73). Indeed, Mikhalkevich et al. demonstrated macrophages irradiation induced an altered secretory phenotype (through human endogenous retroviruses), characterized by an increase of proinflammatory factors, such as IL-6, IL-1 $\beta$, TNF $\alpha$, CCL2, CCL3, CCL8, and CCL20, in addition to an elevated secretion of anti-inflammatory IL-10, which may facilitate their tumorigenic activity (86). In mice xenografted with insulinoma, melanoma or prostate cancer cells and exposed to low radiation doses (2 Gy), macrophages in the TME show increased inducible nitric oxide synthase (iNOS) expression that favors their ability to inhibit abnormal tumor angiogenesis and promote tumor antigen-specific T-cell immunity (87). The activation of a signaling cascade involving NOX2-mediated ROS production, ATM and IRF5 is required in 2 Gy-irradiated macrophages for the acquisition of the RT induced pro-inflammatory phenotype. Moreover, $\mathrm{NOS} 2{ }^{+} \mathrm{CD} 68^{+}$macrophages are enriched in tumor lesions from patients with colorectal cancer showing good response to neoadjuvant RT (88). Interestingly, a study based on the observation that human papillomavirus 16 (HPV16)-positive head and neck cancers are more sensitive to immunotherapy than HPV16 specimens found that IL- 6 production by HPV $16^{+}$cancer cells specifically favors RT-induced macrophage polarization toward an immunostimulatory phenotype, which is linked to the establishment of an effective anti-tumor immunity (89). Furthermore, blockade of IL4/IL14 signaling by inhibiting STAT6 suppresses the induction of the immunosuppressive phenotype in the THP1 human macrophage cell line, thus reducing the radiation resistance of the co-cultured inflammatory breast cancer cell lines (90). Macrophage behavior following radiation appears versatile and influenced by the TME. However, 2 Gy irradiation of mouse macrophages reduces their ability to induce $\mathrm{T}$-cell proliferation in vitro (91, 92). The positive impact of macrophages following RT remains largely debated because despite the induction of a proinflammatory phenotype, these cells are unfavorable to the establishment of an effective anti-tumor immune response in multiple contexts. In agreement, macrophage depletion upon 10 Gy RT promotes the adaptive immunity and the response to immune checkpoint inhibitors in mice harboring MC38 colorectal cancer cell xenografts (93). Similarly, 25 Gy 
irradiation and 4 Gy fractionated irradiation of mice xenografted with TRAMP-C1 prostatic cancer cells drive ARG1, iNOS and COX2 expression in macrophages. Moreover, the transfer of macrophages isolated from 25 Gy-irradiated tumors increases tumor growth in vivo (94). Finally, CD163 expression, a marker of immunosuppressive macrophages, is negatively associated with survival in patients with HPV16- head and neck primary tumors after RT with various radiation modalities (95).

Although macrophage plasticity in response to the radiation modalities and TME might favor the anti-tumor immune response and radiation resistance, this cell type has been constantly associated with RT-induced toxicity. In mice exposed to localized colon irradiation, depletion of monocytes and macrophages using clodronate is associated with a major reduction of colon infiltration by $\mathrm{T}$ lymphocytes, an 1.4-fold decrease of colon vascularization and lower collagen deposition in crypts, suggesting a reduction of the fibrotic process (96). In mice, irradiation of the upper region of the right lung (20 Gy as single dose or fractionated) leads rapidly (72 hours) to infiltration by macrophages and neutrophils and later to collagen deposition and fibrosis (week 26) (97). Interestingly, in mice, soy isoflavones increase $\operatorname{Arg}^{+}$immunosuppressive macrophage survival, avoid immunostimulatory phenotype activation in interstitial macrophages, and reduce neutrophil recruitment following 10 Gy irradiation to the lung (98). Similarly, treating mice with the anti-inflammatory fucoidan reduces the accumulation of macrophages and neutrophils after $10 \mathrm{~Gy}$ irradiation that is associated with decreased expression of CXCL1, TIMP1, MCP1 and MIT2 (99). These modifications in the early response to RT are particularly important because lung fibrosis was strongly decreased in this model. Co-inhibition of PDGF and TGF $\beta$ in mice during and after lung irradiation (20 Gy) strongly reduces lung fibrosis and increases mouse survival. Similar results and the concomitant reduction of immunosuppressive macrophage infiltration in lungs were obtained by blocking connective tissue growth factor (CTGF) in mice $(100,101)$. CTGF blockade might abrogate TGF $\beta$ downstream effects (cell mobility and epithelial-to-mesenchymal transition, EMT) on MSCs, fibroblasts and endothelial cells (101), and deeply remodels the lung immune infiltration following RT (102). In a rat model of RT-induced gut toxicity, 25 Gy irradiation of the gut led to increased expression of MMP2, MMP9, VEGF, TGF $\beta$, endostatin and angiostatin. These factors might strongly influence the behavior of endothelial cells (103). In conclusion, most cellular responses associated with lung fibrosis are caused by or linked to infiltration by macrophages with a proinflammatory phenotype.

\section{Endothelial Cells}

The establishment of an effective anti-tumor immune response depends on the functionality of the tumor vasculature. Yet, ionizing radiation profoundly modifies blood vessel functionality by activating ATM signaling, oxidative stress responses and DAMP signaling in endothelial cells that ultimately drive NRF2, AP-1 and NF- $\kappa$ B activation [for review see Baselet et al. (104)]. Interestingly, genetic engineering allows the specific sensitization to RT of the vasculature or of tumor cells through the conditional knockout of the Atm gene in cancer or endothelial cells in a mouse model of lung adenocarcinoma. Strikingly, RT anti-tumor activity is not increased in mice where Atm was knocked out specifically in endothelial cells, despite the massive destruction of the tumor vasculature. Conversely, Atm knockout specifically in cancer cells strongly increases the response to RT (105). Hence, in some RT modalities, endothelial cells can be killed by radiation, but this does not seems to contribute significantly to the sensitivity to RT. It is noteworthy that regarding ATM signaling in a tumor context, Zhang et al. demonstrated that ATM regulates IFN signaling in pancreatic cancer such that its inhibition induces TBK1 activation and IFN-I production that is further enhanced by RT (106). In vivo, the authors showed that ATM silencing increased IFN signaling as well as PD-L1 expression. Consequently, ATM-deficient tumors are sensitized to combination therapy with PD-L1 blockade and RT. The regulation of IFN signaling by ATM represents a connection between the radiation-induced DDR and innate immunity that can be exploited to enhance the efficacy of immune checkpoint blockade therapy.

Exposure of human coronary artery endothelial cells to $10 \mathrm{~Gy}$ irradiation (single dose or five fractions of $2 \mathrm{~Gy}$ ) leads to higher modifications of the DDR, immune response, apoptosis and inflammatory response gene expression profile upon fractionated treatment. DDR and the expression of DNA repair genes were decreased in irradiated cells, while expression of ICAM1, VCAM1, CXCL10, CXCL11, CXCL12, CXCL16, CCL2, CCL5, CCL20, CCL23, IFNE, IFNA4, IL1A, IL1B, IL15, TGFB1, TGFB1, CXC4, CXCR7 and FAS was increased (107). In TNF $\alpha$ pre-activated endothelial cells, exposure to low radiation doses (0.3 to $0.6 \mathrm{~Gy})$ reduces leukocyte adhesion, unlike moderate doses (2-5Gy). This suggests that differences in radiation doses might confer to endothelial cells the capacity to support $(<2 \mathrm{~Gy})$ or reduce $(<0.5 \mathrm{~Gy})$ immune cell extravasation (108). Similarly, 26 Gy irradiation of endothelial cells increases cancer cell/ endothelial cell adhesion in vitro, and this effect is enhanced by pre-incubation with TNF $\alpha$. Furthermore exposure of human umbilical vein endothelial cells (HUVEC) to 2 or 4 Gy photon irradiation increases the endothelial cell monolayer permeability for tumor cells through a mechanism involving ADAM10mediated degradation of VE-cadherin (109). Thus, through the induction of an inflammatory response, radiation reduces the endothelial barrier permeability and promotes the release of proinflammatory factors that orchestrate the architecture of the tumor immune microenvironment. The exact contribution of endothelial cells to the induction or the suppression of an effective anti-tumor immune response upon RT remains unclear. Nevertheless, the implication of these cells in RTinduced cardiac toxicity is well established through the induction of cell death, premature senescence and prothrombotic reactions $(110,111)$. Moreover, deletion of plasminogen activator inhibitor type- 1 in endothelial cells protects mice from RT-induced colitis through a reduction of 
macrophage accumulation and collagen deposition in the irradiated colon (112). Similarly, inhibition of radiationinduced CCL2 signaling preserves lung endothelial cell function in irradiated mice, reduces macrophage and neutrophil contribution to lung fibrosis, and metastatic colonization (113).

\section{Fibroblasts and Mesenchymal Stem Cells}

After cancer cells, fibroblasts are the main cell population in the TME of many solid cancers. They play a crucial role in the TME and cancer progression, and they are usually referred to as cancer-associated fibroblasts (CAFs). CAFs are considered to be extremely resistant to RT, and indeed they are not killed by exposure to high radiation doses (18 Gy) $(114,115)$. Fibroblasts are normally in a resting state with low transcriptional and metabolic levels, but they can change to a more active phenotype following RT. Once activated, fibroblasts start to produce and secrete many factors, such as cytokines, ROS, nitric oxide (NO) and extracellular matrix components (116), that strongly influence the TME effects on immune and cancer cells. CAFs have been extensively described as suppressor cells for both innate and adaptive immune responses. After a single dose (18 Gy) or fractionate irradiation (3 x 6 Gy), CAFs can inhibit the migratory capacity and pro-inflammatory cytokine secretion of immunostimulatory macrophages, redirecting them toward an immunosuppressive phenotype (117). RT-treated CAFs ( 1 x 18 Gy or 4 × 2 Gy) also suppress Tcell function and migration through the secretion of soluble factors that inhibit IFN $\gamma$ and TNF $\alpha$ production by T cells (114).

The CAF secretome after irradiation influences also cancer cells behavior. Upon activation induced by irradiation $(1.8,9$, or $18 \mathrm{~Gy})$, CAFs isolated from human colorectal cancers secrete IGF1 that then activates the mTOR pathway in cancer cells, thus promoting their survival and proliferation, especially at high radiation dose (115). Similarly, in a model of pancreatic ductal adenocarcinoma, conditioned medium from irradiated fibroblasts (5 Gy) increases iNOS/NO signaling in cancer cells, activating the production of pro-inflammatory cytokines through NF-kB signaling. The activation of this pathway increases cancer cell aggressiveness, with higher cell growth, migration invasion and metastatic potential (118). CAFs promote cancer cell aggressiveness also by secreting factors that induce EMT. For instance, upon exposure to $4 \mathrm{~Gy}$, CAFs secrete CXCL12 and IL-6 that drive EMT in pancreatic cancer cells, making them more prone to migration and invasion (119). Also, RT-induced-CAF-dependent IL-6 expression plays a crucial role in EMT of esophageal adenocarcinoma cells, as shown by monitoring the effect of conditioned medium of fibroblasts isolated from patients after treatment (chemotherapy and radiotherapy) (120). This CAF-dependent mesenchymal phenotype is also associated with resistance to radiotherapy (120). Most importantly, CAFs influence the TME also by remodeling its structure (121) through the production of collagen, fibronectin and other extracellular matrix (ECM) components (122). Following RT, this process is accompanied by downregulation of metalloproteinase expression and culminates in the accumulation of ECM components.
ECM restructuration and the pro-inflammatory and highly oxidative microenvironment created by CAFs can lead to tissue fibrosis (121)

A promising approach to overcome RIF is based on the use of MSCs (123). MSCs migrate to the injured tissue also thanks to the expression of CXCR1 that binds to IL- 8 produced by RTdamaged cancer cells $(124,125)$. There, they can regenerate the damaged tissue through their ability to differentiate into various cell types. Several evidences highlight MSC important contribution to $\mathrm{RT}$-induced vascular injury repair by differentiating into endothelial cells $(124,126)$. MSC role in RIF repair is also mediated by their immunomodulatory secretome that counteracts inflammation and oxidative stress in fibrotic tissue caused by CAFs and cancer cells $(127,128)$. Inhibition of RT-derived inflammation by MSCs also decreases the risk of lung metastases after irradiation (124). Moreover, in a mouse model of melanoma, the response to RT (2 Gy) is enhanced by associating local or systemic injection of MSCs (129). Similar results were obtained in a mouse model of irradiated glioblastoma (10 Gy) (125). Hence, MSC administration appear to be a key strategy to counteract RT side effects and improve its outcome.

Altogether, these observations highlight that common mechanisms are involved in RT-induced anti-cancer immunity and side effects. Indeed, the amplification of the anti-tumor immunity and deleterious fibrosis and necrosis are the consequence of bystander transmission of ROS-induced cell stress through macrophages, endothelial cells, fibroblasts and MSC sterile-inflammatory responses. A new component, called STING-mediated innate immune signaling, has recently be added to this complex anti-cancer immunity-side effects crosstalk. Accumulating evidences tend to position this pathway at the interface between RT-induced immunity and toxicity.

\section{THE STING PATHWAY IN RT INDUCED IMMUNITY}

To detect pathogens, the mammalian innate immune system has evolved distinct sensing strategies, including extranuclear DNA recognition. Nucleic acid-sensing is based on cytosolic receptors that detect extranuclear DNA or extracellular RNA as DAMP signals. These pathways can trigger cell death in malignant cells and recruit immune cells into the TME, and are investigated as promising adjuvants in cancer immunotherapies (130). To date, one of the major pathways that mediate the immune response to DNA is governed by the DNA-sensing enzyme cyclic guanosine monophosphate-adenosine monophosphate (cyclic GMPAMP) synthase (cGAS) $(131,132)$. cGAS is activated upon binding to double-stranded DNA (dsDNA). Activated cGAS converts adenosine $5{ }^{\prime}$-triphosphate (ATP) and guanosine 5' triphosphate (GTP) into cyclic GMP-AMP (cGAMP). Cyclic GAMP acts as a secondary messenger that binds to and activates stimulator of interferon genes (STING), ultimately triggering a variety of inflammatory effector responses (133). In addition, retinoic acid inducible gene-I (RIG-I) and melanoma 
differentiation-associated protein 5 (MDA5) might induce growth inhibition or apoptosis of different cancer cell types upon activation by RNA ligands in an IFN-dependent or -independent manner (134). This review focuses only on the cGAS-STING pathway.

\section{Radiation Induces Cytosolic Double- Stranded DNA Accumulation That Is Sensed by the cGAS-STING Pathway}

Radiation-induced chromosomal aberrations represent an early marker of late effects, including cell killing and transformation (135). Micronuclei are small nuclei found in the cytoplasm in addition to the primary cell nucleus of mammalian cells and are produced during mitosis by various mechanisms (e.g. acentric fragments, multicentric chromosomes, etc.) (136). When damaged cells go through mitosis, micronuclei may follow four major possible fates: degradation, reincorporation, extrusion, and persistence (137). Micronuclei may be degraded in the cytoplasm after collapse of their nuclear envelope, leading to irreversible loss of compartmentalization during interphase, and are characterized by chromatin compaction (138). Hatch and colleagues observed multiple foci or a single large focus of accumulated $\gamma$ - $\mathrm{H} 2 \mathrm{AX}$ in approximately $60 \%$ of disrupted micronuclei located in the cytosol of cancer cells, indicating that DNA damage accumulation is strongly correlated with micronucleus disruption (138). In the context of ionizing radiation, micronucleus production increases in function of the irradiation dose (139) and is correlated with cell killing. Moreover, Piron et al. demonstrated that mis- or un-repaired DNA double strand breaks might lead to micronucleus formation and to mitotic death of damaged cells (140). However, these data suggest that acute cell death associated with low doses and low dose-rate of ${ }^{125}$ I-labeled antibodies (Auger electron emitters) is not due to defective detection of DNA damage by the cells. Impaired repair of double strand breaks might be involved in the low dose-rate efficacy of TRT using ${ }^{125}$ I-labeled antibodies in a non-dependent dose-effect relationship (140).

Accumulation of dsDNA in disrupted micronuclei present in the cell cytosol can explain the activation of the cGAS-STING pathway following RT (141). When the nuclear envelope of a micronucleus collapses (138), the DNA content is detected by the cGAS-based surveillance mechanism that links genome instability to innate immune responses (141). Harding et al. showed that cell cycle progression through mitosis following dsDNA breaks induced by 10-20 Gy RT, leads to the formation of micronuclei, which precede activation of inflammatory signaling and are a repository for cGAS (142). For instance, Vanpouille-Box et al. found that cytoplasmic dsDNA was about ten times more abundant in TSA cells exposed to a single dose of 8 Gy or 3 fractions of 8 Gy (X-rays) compared with untreated cells. This was associated with the release of IFN- $\beta$ and increased expression of IFNAR1 and CXCL10 (143). In addition, it is unclear how cytoplasmic dsDNA is transferred from cancer cells to immune cells, especially to DCs, although transfer via exosomes has been suggested $(144,145)$.
Radiation-induced pro-immunogenic effects in cancer cells are observed in conventional RT with radiation doses from 2 Gy up to $30 \mathrm{~Gy}$ or more; however, the optimal radiation regimen to induce a clinically relevant anti-tumor immunity remains to be defined $(13,146)$. The previous examples about micronucleus and cytosolic dsDNA accumulation suggest a complex relationship between irradiated tumor and host immune system. Vanpouille-Box et al. investigated dsDNA content in the cytosol of cells exposed to radiation (X-rays) doses ranging from 0 Gy to $30 \mathrm{~Gy}$ in different murine and human cancer cell lines (143). Surprisingly, they observed that dsDNA accumulates in the cytosol up to a critical threshold when it abruptly decreases at doses between 12 to $18 \mathrm{~Gy}$. The authors demonstrated that doses above this threshold do not confer immunogenicity, mainly due to the dose-dependent upregulation of three-prime repair exonuclease 1 (TREX1). TREX1 is a DNA nuclease with a main role in the degradation of cytoplasmic double- and singlestranded DNA (147). Vanpouille-Box et al. found in TSA cells that upon RT (single doses above $12 \mathrm{~Gy}$ ), cytosolic dsDNA is cleared by TREX1, precluding the activation of the cGAS pathway to induce type I IFN, therefore abolishing the RTinduced anti-tumor immune response $(143,148)$.

Cytosolic leakage of mitochondrial DNA (mtDNA) also results in activation of the cGAS-STING pathway (149-151). Mitochondria are sources of ROS that plays a major role in the induction and persistence of oxidative stress following exposure to radiation (152). They are also involved in non-targeted radiation effects $(153,154)$, suggesting their implication in radiation-induced systemic responses. However, mtDNA is not the primary target of radiation. Friedland et al. used track structure simulations to demonstrate that the probability of DNA double strand breaks induction in mtDNA is about $0.03 \%$ at 1 Gy of $\gamma$-rays or densely ionizing radiation (155). The involvement of mitochondria in late radiation effects is more likely to be an indirect consequence of ROS generation after irradiation and of the nucleus-mitochondrion signaling pathway. Nevertheless, mtDNA might leak in the cytosol after a direct hit from a charged particle, such as beta particles (e.g. ${ }^{177} \mathrm{Lu},{ }^{90} \mathrm{Y}$ radionuclides), alpha particles (external $\alpha$ beam or ${ }^{225} \mathrm{Ac} /{ }^{213} \mathrm{Bi}$ radionuclides), or Auger electrons (e.g. ${ }^{125} \mathrm{I}$ ).

Altogether, these observations highlights the facts that radiation-induced micronuclei and dsDNA are required for anti-tumor immunity induction via cGAS sensing and STING activation. However, the radiation regimen (type of particles, dose, fractions, etc.) to obtain these effects in patients is not known yet. In 2014, a phase II clinical trial was started in patients with NSCLC who progressed after chemotherapy and with at least two measurable disease sites to determine whether radiation and immunotherapy with ipilimumab can stimulate the immune system and stop the growth of tumors that are outside the field of radiation (NCT02221739). Patients receive ipilimumab within $24 \mathrm{~h}$ of local RT initiation ( $6 \mathrm{~Gy} \times 5$ fractions, 3D-CRT or IMRT). In the case of lack of response, a second phase II trial will be performed with a new RT regimen ( $9.5 \mathrm{~Gy} \times 3$ fractions).

\section{cGAMP in Bystander Immunity}

The role of cGAS and STING in the bystander communication between tumor and non-tumor cells is linked to the concept of 
cGAMP, a second messenger that activates the STING pathway. Deng et al. demonstrated that exogenous cGAMP treatment promotes the antitumor efficacy of radiation (156). In wild-type mice, the cGAMP and radiation combination reduces tumor burden more effectively than cGAMP or radiation alone. Moreover, about $70 \%$ of mice in the combination arm showed complete tumor regression at treatment completion (156). All these data indicate that boosting STING signaling activation can enhance tumor growth inhibition after irradiation. Moreover, Liu et al. demonstrated that in mice grafted with B16-OVA melanoma cells (intravenous injection to model lung metastases), nanoparticle-cGAMP inhalation synergizes with fractionated RT $(8 \mathrm{~Gy} \times 3$ in the right lung) to generate a potent antitumor immunity against melanoma metastases in both irradiated and non-irradiated lungs (157). This combination led to metastasis growth inhibition in the irradiated and non-irradiated lung, and complete regression of lung metastases in some mice, through TME remodeling (157).

Cytoplasmic cGAMP can diffuse to adjacent cells via gap junctions $(158,159)$. Ablasser and colleagues clearly described a unique immune signaling mechanism that comprises cGAMP production by cGAS in the sensing cell, which is transmitted through gap junctions to bystander cells, leading to remote STING activation and subsequent antiviral immunity. Noteworthy, type I IFN-dependent induction of antiviral immunity in bystander cells takes considerably longer, given the requirement of de novo transcription and translation. Therefore, cancer cell-derived cGAMP following irradiation could provide a fast antitumor immune response. These data suggest that bystander activation and signal amplification could have a beneficial role in RT; however, cGAMP transfer might at the same time aggravate cancer resistance and the metastatic potential of STING-dependent tumors. For instance, Chen et al. demonstrated that functional CX43-based gap junctions between cells allow cGAMP transfer from cancer cells to astrocytes (159). This leads to the activation of the STING pathway and the release of cytokines, including IFN $\alpha$ and TNF, which provide a growth advantage to brain metastatic cells by protecting them against physiological and chemotherapeutic stresses. Unlike the transfer of cGAMP to bystander cells that intensifies the immune response, cGAMP transfer from brain metastatic cells to neighboring astrocytes triggers downstream signaling that supports metastatic outgrowth.

Schadt et al. proposed that cGAMP, and not cytoplasmic dsDNA, is transferred from cancer cells to DCs in a CX43dependent manner, thus enabling the production of type I IFN and antitumor immunity priming (160). This connexindependent transfer of cGAMP was corroborated by Pepin et al., who observed the potentiation of macrophages cultured with the conditioned medium of cGAMP producing cells (161). Similarly, Marcus et al. showed that cGAMP, and not dsDNA, is transferred from cancer cells to DCs (162). Indeed, experiments using transplantable tumor models in STING- and cGASdeficient mice revealed that cGAS expression by tumor cells is critical for tumor rejection by NK cells. Conversely, cGAS expression by host immune cells is not necessarily required, suggesting that tumor-derived cGAMP is transferred to nontumor cells where it activates STING (162). These observations raise questions about the molecular mechanism involved in the fusion of sEVs purified from tumor cells with recipient (bystander) cells. Indeed, it would be important to know what surface molecules allow their fusion with the recipient cell membrane for cGAMP or dsDNA delivery into the cytosol. Alternatively, other mechanisms could also contribute, such as formation of channels between the apposed membranes of a sEV and the recipient cell (163).

Overall, these studies demonstrated that cancer cell irradiation leads to cGAMP release in immune cells and that STING has a major role in immune cells in radiation-induced immunity, while it is not required in tumor cells. Furthermore, Bakhoum et al. showed that the cGAS-STING pathway is activated in human cancer cells with chromosomal instability. Improper segregation of chromosomes during cell division leads to the formation of unstable micronuclei, releasing their DNA into the cytosol. In this study, Bakhoum et al. demonstrated that inflammatory response involves activation of $\mathrm{NF}-\kappa \mathrm{B}$ signaling and promotes metastasis in a STING-dependent manner (164). Accordingly, our recent data suggests that STING expression in lung cancer cells might contribute to tumor formation and that low STING expression in these cells fails to induce type-I IFN expression and potentially favors the establishment of an immunosuppressive microenvironment (165). Figure 1 summarize the bystander communication between cancer cells and immune cells.

\section{The STING Pathway in the Induction of the Senescence-Associated Secretory Phenotype and of RT-Induced Adverse Effects}

Through DDR activation, ionizing radiation is a potent driver of accelerated cancer cell senescence, a process that involves ATM, ATR, DNA-dependent protein kinases (166), p53, P16INK4a, p21WAF1, CHEK1 and CHEK2 (167), in breast cancer, colon carcinoma, neuroblastoma and fibrosarcoma. Although senescent cells have exited the cell cycle, they can maintain an active metabolic activity and participate in resistance to therapy and disease progression (168). Indeed, senescent cells can secrete many different bioactive molecules, such as cytokines, proteases and growth factors that influence and shape the surrounding microenvironment. This has been described as SenescenceAssociated Secretory Phenotype (SASP) (169). Among the many SASP factors, IL-6, CCL5, CXCL12, CCL2 and IL-8 have a particularly important role in supporting cancer cell metastasis formation and the establishment of an immunosuppressive microenvironment, although in some cancer models they can be found in the immune stimulatory secretome (Figure 2).

As RT can induce tumor cell senescence, NK cell recruitment by SASP factors could be a general mechanism by which NK cells help to clear tumor cells in response to senescence-inducing therapies (170). Indeed, in a mouse model of radiation-induced osteosarcoma, the retinoblastoma tumor suppressor gene (RB1) is required for SASP expression and infiltration of NK T-cells in 


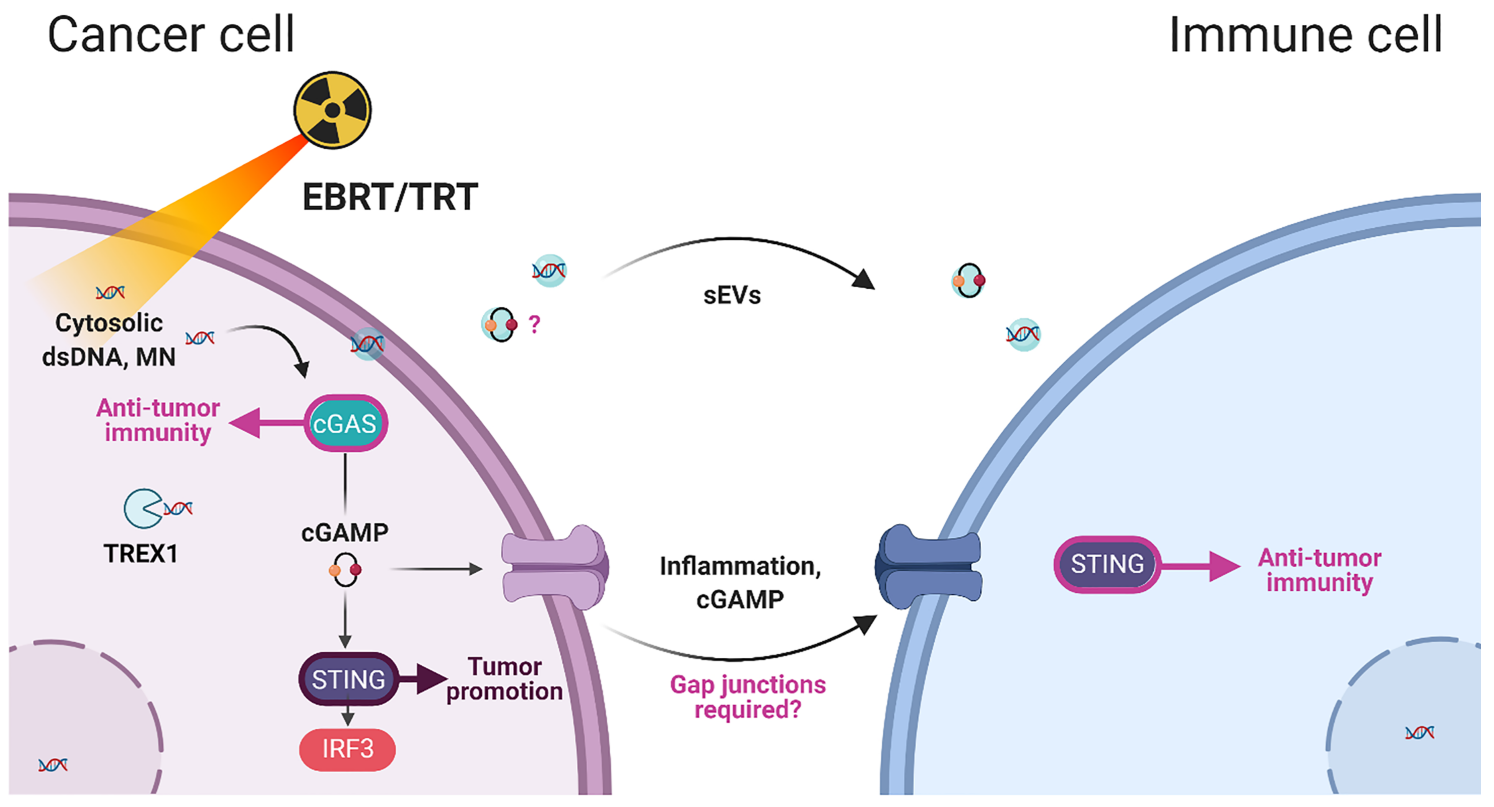

FIGURE 1 | Summary of cancer-immune cell interactions after irradiation (EBRT, external beam radiation therapy; TRT, Targeted Radionuclide Therapy) and the involvement of dsDNA, double-stranded DNA; MN, micronucleus; sEVs, small extracellular vesicles; and cGAMP, cyclic GMP-AMP in bystander immunity.

bones of mice exposed to carcinogenic doses of ${ }^{45} \mathrm{Ca}$ (four postpartum injections; low energy beta-emitting particles) (171). Il-6 and MIP2 (the murine homolog of IL-8) induce neutrophil accumulation in vivo (172), and MIP2 is also implicated in NK T-cell recruitment to the spleen (173). Kansara et al. showed that $C d 1^{-1-}$ mice, lacking NK T cells, are predisposed to ${ }^{45} \mathrm{Ca}$-induced osteosarcoma development when crossed with $\operatorname{Trp} 53^{+/-}$mice, consistent with previous findings that NK T-cells play an important role in sarcoma development (174). Growth inhibition of IL-6-deficient osteosarcoma cell lines in wild type mice is accompanied by NK T-cell infiltration, further supporting a role for these cells in host-dependent tumor suppression in vivo. Interestingly, in this model, IL-6 not only recruits NK cells that limit tumor growth, but also reinforces the senescence phenotype through autocrine and paracrine mechanisms (171), indicating that bystander (initially) nonsenescent tumor cells can be targeted as well (Figure 2, left panel). Better understanding how radiation induces SASP factors (dose, fractions, etc.) production by osteoblasts could be beneficial for the management of patients with bone metastases treated with Xofigo ${ }^{\mathrm{TM}}{ }_{\left({ }^{223} \mathrm{Ra}\right.}$, alpha emitting particles) among whom some reported jaw osteonecrosis (175).

Extranuclear DNA sensing via the cGAS-STING pathway might play a major role in radiation-induced SASP. The involvement of cGAS in senescence induction has been shown in primary human lung cells (IMR90) in which cGAS and STING knockdowns abolish expression of key SASP-related markers (p16INK4a, IL-8, CXCL1,2,3, IL-6 and CCL2) upon senescence induction with HRasV12 or etoposide. Senescence induction is also reduced in STING knockout mice, as indicated by the absence of hair greying three months after sublethal irradiation, and the impaired immunosurveillance against $\mathrm{N}$ Ras (liver tumor formation) (176). Senescence induction in p53proficient cells is an important protection mechanism against cell transformation upon oncogenic signaling activation (PTEN loss, Ras signaling). Hence, activation of the cGAS-STING pathway in cells during oncogene-induced SASP is also tightly linked to the expression of the cytoplasmic exonuclease MRE11, TREX1 and DNase2 that rapidly degrade cytoplasmic DNA fragments (177, 178). Whereas DNases mediate the clearance of dsDNA, an excessive amount of DNA escaping from DNases is responsible for induction of type I IFN, through the activation of DNA sensors such as the cGAS-STING pathway. Conversely, cGAS, STING, TBK1 and IRF3 knockdowns are characterized by reduced p21 expression in HeLa cells that leads to higher mitotic activity and ultimately chromosomal instability (179). Altogether, these observations demonstrate that the cGASSTING pathway might play an important role in maintaining chromosome integrity through senescence induction, and that in this context this pathway also contributes to SASP instauration in cancer cells. However, senescence induction and SASP are intrinsically linked to a functional p53 pathway, and the functionality of the STING-IRF3 pathway in cancer cells harboring p53 mutations has not been investigated yet.

On the other hand, SASP induction following ionizing radiation promotes tissue fibrosis (180). For instance, type-II pneumocyte (181) and alveolar stem cell (182) senescence contributes to RIF in lungs. Similarly, endothelial cell senescence induced by RT is causal in the establishment of cardiovascular disease (183). Considering the critical role of STING signaling in the expression of the complete SASP phenotype, STING expression in endothelial cells and 


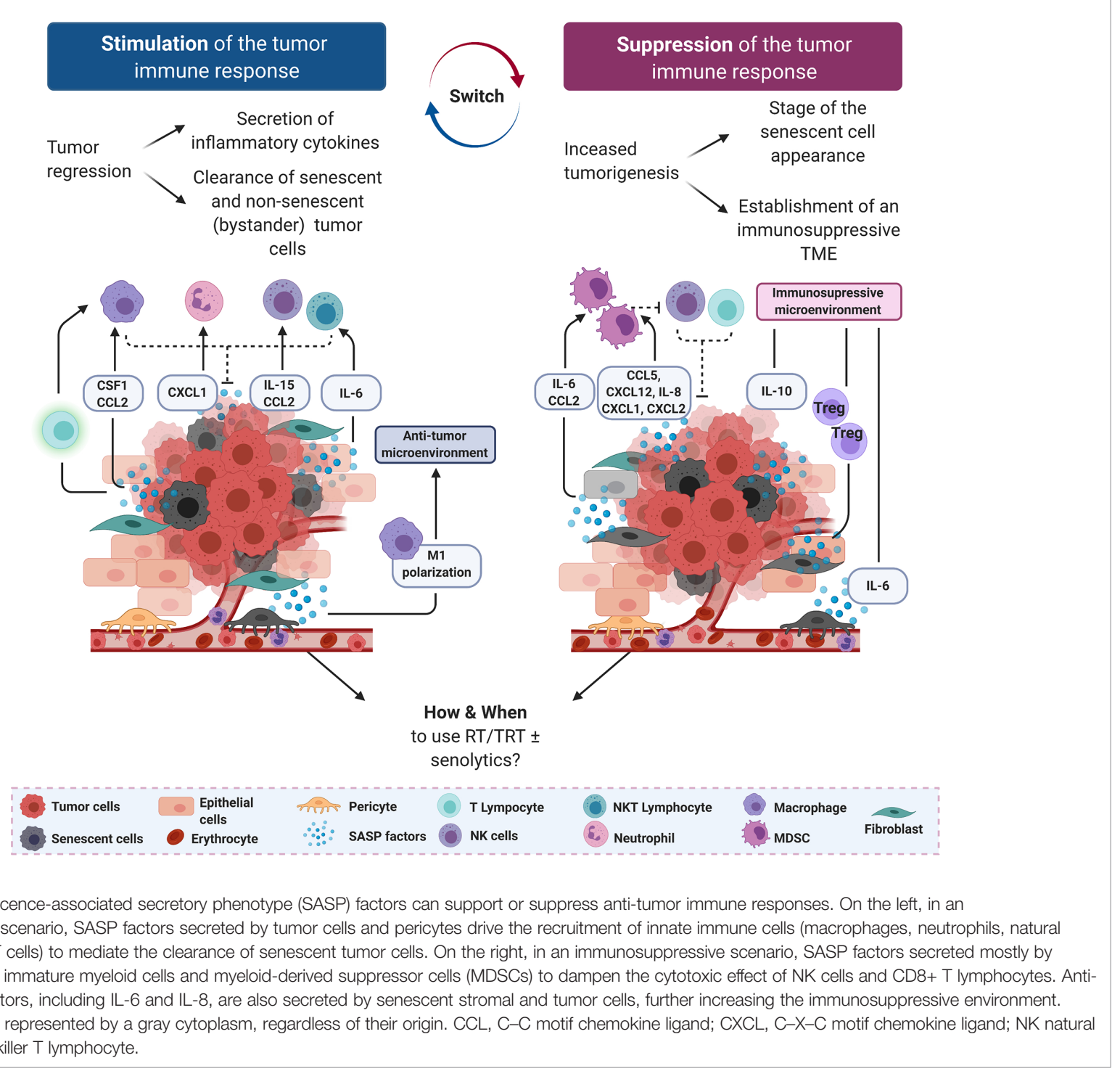

pneumocytes might directly contribute to these RT-induced deleterious effects. In vitro, irradiation (2 Gy) of human coronary artery is sufficient to activate the STING pathway and consequently type-I IFN expression (184). Furthermore, STING contributes to cardiac hypertrophy and fibrosis in a model of pressure-overload cardiac hypertrophy through the recruitment of inflammatory macrophages and the release of angiotensin-II (185). STING might also play an important role in the endothelial cell response to RT. Indeed, tumor-derived cGAMP can drive endothelial cell activation, leading to upregulation of adhesion molecules (V-CAM1, I-CAM1) and T-cell recruitment. Constitutive STING activation (due to a mutation) drives microvessel thrombosis and pulmonary syndrome development in infants through an autoimmune reaction, leading to chronic inflammation and macrophage recruitment (186). This reaction that involves endothelial cell dysfunction and chronic sterile inflammation is reminiscent of RT-induced lung fibrosis and maculopathy. All these data suggest that STING signaling in endothelial cells might contribute to the anti-tumor immunity through recruitment of immune cells. However, most of the observation made in vivo and in patients suggest that endothelial cell STING signaling could also be an important player in RT-induced cardiac toxicity (187) and possibly lung fibrosis. The impact of STING expression in fibroblasts on RT response remains to be elucidated. Finally, these studies suggest that because many current standard treatments for cancer can induce senescence, which can have wide-ranging effects, some patients might benefit from the addition of senolytic therapy to inhibit the protumorigenic stroma.

Altogether, these observations highlight the key position of STING signaling following RT where it contributes to cancer immunogenicity, DC activation and anti-tumor T-cell response, while simultaneously playing a central role in SASP induction in many cell types. This might be an initiating event towards the aggravation of RT-induced cytotoxicity. 


\section{CONCLUDING REMARKS}

In the past decade, $\mathrm{RT}$ entered the era of personalized medicine, thanks to the striking improvements in radiation delivery, treatment planning optimization, and better understanding of the cancer response. However, the next challenge is to identify the optimal RT regimen to induce a clinically relevant antitumor immune response. Indeed, bystander and abscopal effects have been demonstrated in preclinical studies and in some clinical cases, but the exact dose threshold and range need to be defined in function of the tumor type and characteristics, and the patient's immune status. We hypothesize that radiation could be used as an immunological adjuvant, by lowering the dose per fraction (and/or the total dose) in "hot" tumors, specifically to preserve the viability of intra-tumor lymphocytes. Conversely, the dose could be increased in "cold" tumors. However, healthy organs at risks and the TME often limit the radiation regimen possibilities due to the high risk of adverse toxicities. For instance, radiation reduces the endothelial barrier permeability, facilitating the release of pro-inflammatory factors that orchestrate the architecture of the tumor immune microenvironment. Also, RT-activated macrophages have been repeatedly associated with RT-induced toxicity. Therefore, it is important to find how to modulate macrophage activation to avoid deleterious phenotypes.

$\mathrm{RT}$ involves the activation of an anti-tumor response through cytosolic dsDNA sensing by the cGAS-STING pathway. However, a major open question is how to choose the most effective radiation regimen to increase dsDNA accumulation without reaching the critical threshold leading to the activation of DNases, such as TREX1. Interestingly, tumor and immune cells can communicate through the transfer of cGAMP and sEVs, demonstrating that cGAS expression by host immune cells is not necessarily required, while STING is.

Furthermore, there is still an important gap of knowledge on the cGAS-STING pathway role in cancer cell SASP induction upon RT. STING signaling following RT contributes to cancer immunogenicity, DC activation and anti-tumor T-cell response, while simultaneously playing a central role in SASP induction in many cell types. SASP induction is involved and most probably is

\section{REFERENCES}

1. Thames HD, Withers HR, Peters LJ, Fletcher GH. Changes in Early and Late Radiation Responses With Altered Dose Fractionation: Implications for Dose-Survival Relationships. Int J Radiat Oncol Biol Phys (1982) 8:219-26. doi: 10.1016/0360-3016(82)90517-X

2. Thames HD. On the Origin of Dose Fractionation Regimens in Radiotherapy. In: Seminars in Radiation Oncology. WB Saunders (1992). p. 3-9.

3. Moran MS, Schnitt SJ, Giuliano AE, Harris JR, Khan SA, Horton J, et al. Society of Surgical Oncology-American Society for Radiation Oncology Consensus Guideline on Margins for Breast-Conserving Surgery With Whole-Breast Irradiation in Stages I and II Invasive Breast Cancer. Int J Radiat Oncol Biol Phys (2014) 88:553-64. doi: 10.1016/j.ijrobp.2013.11.012

4. Kaidar-Person O, Zagar TM, Deal A, Moschos SJ, Ewend MG, SasakiAdams D, et al. The Incidence of Radiation Necrosis Following Stereotactic Radiotherapy for Melanoma Brain Metastases: The Potential Impact of an initiating event in the aggravation of many RT-induced cytotoxicity events. Radiation dose threshold and SASP are linked through the expression of cytoplasmic DNases, such as TREX1. Once again, the fine-tuning of radiation dose regimens should allow an optimal anti-tumor immune response while limiting adverse effects.

\section{OUTSTANDING QUESTIONS}

- What are the optimal radiation dose regimens and fractions?

- What is the best therapeutic window to enhance RT antitumor immune response?

- How is the cGAS-STING pathway playing an important role in cancer cell SASP induction upon RT?

- What is the impact of STING expression in fibroblasts exposed to radiation?

- In which conditions inhibitors (e.g. ATM, STING) should be concomitantly administered with RT?

- Whether and when, during cancer development, a senolytic treatment or a drug targeting the SASP should be employed?

\section{AUTHOR CONTRIBUTIONS}

The review results from the discussion and the consensus of all authors listed (JC, JF, CU, CB, and J-PP). Literature review on the topic was analyzed, produced and written by JC, JF, CU, CB, and J-PP. All authors contributed to the article and approved the submitted version.

\section{FUNDING}

This work was supported by SIRIC Montpellier Cancer Grant INCa_Inserm_DGOS_12553, by INCa-Cancéropôle GSO, by AVIESAN PCSI [grant number : ASC20025FSA]. 
Hypersensitive Patients for Personalized Strategy. Crit Rev Oncol Hematol (2015) 93:312-9. doi: 10.1016/j.critrevonc.2014.11.004

11. Mole RH. Whole Body Irradiation; Radiobiology or Medicine? Br J Radiol (1953) 26:234-41. doi: 10.1259/0007-1285-26-305-234

12. Formenti SC, Demaria S. Combining Radiotherapy and Cancer Immunotherapy: A Paradigm Shift. JNCI J Natl Cancer Inst (2013) 105:256. doi: 10.1093/jnci/djs629

13. Kumari A, Simon SS, Moody TD, Garnett-Benson C. Immunomodulatory Effects of Radiation: What is Next for Cancer Therapy? Future Oncol (2015) 12:239-56. doi: 10.2217/fon.15.300

14. Dewan MZ, Galloway AE, Kawashima N, Dewyngaert JK, Babb JS, Formenti SC, et al. Fractionated But Not Single-Dose Radiotherapy Induces an ImmuneMediated Abscopal Effect When Combined With Anti-CTLA-4 Antibody. Clin Cancer Res (2009) 15:5379-88. doi: 10.1158/1078-0432.CCR-09-0265

15. Demaria S, Formenti SC. Radiotherapy Effects on Anti-Tumor Immunity: Implications for Cancer Treatment. Front Oncol (2013) 3:128. doi: 10.3389/ fonc. 2013.00128

16. Ngwa W, Irabor OC, Schoenfeld JD, Hesser J, Demaria S, Formenti SC. Using Immunotherapy to Boost the Abscopal Effect. Nat Rev Cancer (2018) 18:313-22. doi: 10.1038/nrc.2018.6

17. Rodriguez-Ruiz ME, Vitale I, Harrington KJ, Melero I, Galluzzi L. Immunological Impact of Cell Death Signaling Driven by Radiation on the Tumor Microenvironment. Nat Immunol (2020) 21:120-34. doi: 10.1038/s41590-019-0561-4

18. Ladjohounlou R, Lozza C, Pichard A, Constanzo J, Karam J, Fur PL, et al. Drugs That Modify Cholesterol Metabolism Alter the P38/JNK-Mediated Targeted and Nontargeted Response to Alpha and Auger Radioimmunotherapy. Clin Cancer Res (2019) 25:4775-90. doi: 10.1158/1078-0432.CCR-18-3295

19. Paillas S, Ladjohounlou R, Lozza C, Pichard A, Boudousq V, Jarlier M, et al. Localized Irradiation of Cell Membrane by Auger Electrons Is Cytotoxic Through Oxidative Stress-Mediated Nontargeted Effects. Antioxid Redox Signal (2016) 25:467-84. doi: 10.1089/ars.2015.6309

20. Paris F, Fuks Z, Kang A, Capodieci P, Juan G, Ehleiter D, et al. Endothelial Apoptosis as the Primary Lesion Initiating Intestinal Radiation Damage in Mice. Science (2001) 293:293-7. doi: 10.1126/science.1060191

21. Nugent S, Mothersill CE, Seymour C, McClean B, Lyng FM, Murphy JEJ. Altered Mitochondrial Function and Genome Frequency Post Exposure to $\gamma$ radiation and Bystander Factors. Int J Radiat Biol (2010) 86:829-41. doi: 10.3109/09553002.2010.486019

22. Walsh DWM, Siebenwirth C, Greubel C, Ilicic K, Reindl J, Girst S, et al. Live Cell Imaging of Mitochondria Following Targeted Irradiation in Situ Reveals Rapid and Highly Localized Loss of Membrane Potential. Sci Rep (2017) 7:46684. doi: 10.1038/srep46684

23. Baskar R, Lee KA, Yeo R, Yeoh K-W. Cancer and Radiation Therapy: Current Advances and Future Directions. Int J Med Sci (2012) 9:193-9. doi: $10.7150 /$ ijms. 3635

24. Kamada T, Tsujii H, Blakely EA, Debus J, De Neve W, Durante M, et al. Carbon Ion Radiotherapy in Japan: An Assessment of 20 Years of Clinical Experience. Lancet Oncol (2015) 16:e93-100. doi: 10.1016/S1470-2045(14)70412-7

25. Montay-Gruel P, Acharya MM, Jorge PG, Petit B, Petridis IG, Fuchs P, et al. Hypofractionated FLASH-RT as an Effective Treatment Against Glioblastoma That Reduces Neurocognitive Side Effects in Mice. Clin Cancer Res (2021) 27:775-84. doi: 10.1158/1078-0432.CCR-20-0894

26. Sawin CT, Becker DV. Radioiodine and the Treatment of Hyperthyroidism: The Early History *. Thyroid (1997) 7:163-76. doi: 10.1089/thy.1997.7.163

27. Van Nostrand D. The Benefits and Risks of I-131 Therapy in Patients With Well-Differentiated Thyroid Cancer. Thyroid (2009) 19:1381-91. doi: 10.1089/thy.2009.1611

28. Gazzilli M, Durmo R, Cossalter E, Cerudelli E, Panarotto MB, Albano D, et al. Three Years' Clinical Practice of Radium-223 Therapy in Patients With Symptomatic Bone Metastases From Metastatic Castrate-Resistant Prostate Cancer: A Single-Centre Experience. Nucl Med Commun (2020) 41:300-7. doi: 10.1097/MNM.0000000000001164

29. Allen BJ. Clinical Trials of Targeted Alpha Therapy for Cancer. Rev Recent Clin Trials (2008) 3:185-91. doi: 10.2174/157488708785700339

30. Pouget J-P, Lozza C, Deshayes E, Boudousq V, Navarro-Teulon I. Introduction to Radiobiology of Targeted Radionuclide Therapy. Front Med (Lausanne) (2015) 2:12. doi: 10.3389/fmed.2015.00012
31. Pressman D, Korngold L. The In Vivo Localization of Anti-Wagnerosteogenic-sarcoma Antibodies. Cancer (1953) 6:619-23. doi: 10.1002/ 1097-0142(195305)6:3<619::AID-CNCR2820060319>3.0.CO;2-Y

32. Strosberg J, El-Haddad G, Wolin E, Hendifar A, Yao J, Chasen B, et al. Phase 3 Trial of 177Lu-Dotatate for Midgut Neuroendocrine Tumors. New Engl J Med (2017) 376:125-35. doi: 10.1056/NEJMoa1607427

33. Strosberg J, Leeuwenkamp O. Siddiqui MohdK. Peptide Receptor Radiotherapy Re-Treatment in Patients With Progressive Neuroendocrine Tumors: A Systematic Review and Meta-Analysis. Cancer Treat Rev (2021) 93:102141. doi: 10.1016/j.ctrv.2020.102141

34. Bodei L, Kidd M, Paganelli G, Grana CM, Drozdov I, Cremonesi M, et al. Long-Term Tolerability of PRRT in 807 Patients With Neuroendocrine Tumours: The Value and Limitations of Clinical Factors. Eur J Nucl Med Mol Imaging (2015) 42:5-19. doi: 10.1007/s00259-014-2893-5

35. Bergsma H, Konijnenberg MW, Kam BLR, Teunissen JJM, Kooij PP, de Herder WW, et al. Subacute Haematotoxicity After PRRT With 177LuDOTA-octreotate: Prognostic Factors, Incidence and Course. Eur J Nucl Med Mol Imaging (2016) 43:453-63. doi: 10.1007/s00259-015-3193-4

36. Bergsma H, van Lom K, Raaijmakers MHGP, Konijnenberg M, Kam BLBLR, Teunissen JJM, et al. Persistent Hematologic Dysfunction After Peptide Receptor Radionuclide Therapy With 177Lu-DOTATATE: Incidence, Course, and Predicting Factors in Patients With Gastroenteropancreatic Neuroendocrine Tumors. J Nucl Med (2018) 59:452-8. doi: 10.2967/ jnumed.117.189712

37. Ball D, Mai GT, Vinod S, Babington S, Ruben J, Kron T, et al. Stereotactic Ablative Radiotherapy Versus Standard Radiotherapy in Stage 1 Non-SmallCell Lung Cancer (TROG 09.02 CHISEL): A Phase 3, Open-Label, Randomised Controlled Trial. Lancet Oncol (2019) 20:494-503. doi: 10.1016/S1470-2045(18)30896-9

38. Tubin S, Khan MK, Salerno G, Mourad WF, Yan W, Jeremic B. MonoInstitutional Phase 2 Study of Innovative Stereotactic Body RadioTherapy Targeting PArtial Tumor HYpoxic (Sbrt-PATHY) Clonogenic Cells in Unresectable Bulky non-Small Cell Lung Cancer: Profound Non-Targeted Effects by Sparing Peri-Tumoral Immune Microenvironment. Radiat Oncol (2019) 14:212. doi: 10.1186/s13014-019-1410-1

39. Tubin S, Gupta S, Grusch M, Popper HH, Brcic L, Ashdown ML, et al. Shifting the Immune-Suppressive to Predominant Immune-Stimulatory Radiation Effects by SBRT-PArtial Tumor Irradiation Targeting HYpoxic Segment (Sbrt-Pathy). Cancers (Basel) (2020) 13(1):50. doi: 10.3390/ cancers 13010050

40. Trifiletti DM, Lee C-C, Kano H, Cohen J, Janopaul-Naylor J, Alonso-Basanta M, et al. Stereotactic Radiosurgery for Brainstem Metastases: An International Cooperative Study to Define Response and Toxicity. Int $J$ Radiat Oncol Biol Phys (2016) 96(2):280-8. doi: 10.1016/j.ijrobp.2016.06.009

41. Lehrer EJ, McGee HM, Peterson JL, Vallow L, Ruiz-Garcia H, Zaorsky NG, et al. Stereotactic Radiosurgery and Immune Checkpoint Inhibitors in the Management of Brain Metastases. Int J Mol Sci (2018) 19(10):3054. doi: 10.3390/ijms19103054

42. Kohutek ZA, Yamada Y, Chan TA, Brennan CW, Tabar V, Gutin PH, et al. Long-Term Risk of Radionecrosis and Imaging Changes After Stereotactic Radiosurgery for Brain Metastases. J Neurooncol (2015) 125:149-56. doi: 10.1007/s11060-015-1881-3

43. Constanzo J, Masson-Côté L, Tremblay L, Fouquet JP, Sarret P, Geha S, et al. Understanding the Continuum of Radionecrosis and Vascular Disorders in the Brain Following Gamma Knife Irradiation: An MRI Study. Magnet Resonance Med (2017) 78:1420-31. doi: 10.1002/mrm.26546

44. Constanzo J, Midavaine É, Fouquet J, Lepage M, Descoteaux M, Kirby K, et al. Brain Irradiation Leads to Persistent Neuroinflammation and LongTerm Neurocognitive Dysfunction in a Region-Specific Manner. Prog Neuropsychopharmacol Biol Psychiatry (2020) 102:109954. doi: 10.1016/ j.pnpbp.2020.109954

45. Kolesnick R, Fuks Z. Radiation and Ceramide-Induced Apoptosis. Oncogene (2003) 22:5897-906. doi: 10.1038/sj.onc.1206702

46. Daigle JL, Hong J-H, Chiang C-S, McBride WH. The Role of Tumor Necrosis Factor Signaling Pathways in the Response of Murine Brain to Irradiation. Cancer Res (2001) 61:8859-65.

47. Burger PC, Mahaley MS, Dudka L, Vogel FS. The Morphologic Effects of Radiation Administered Therapeutically for Intracranial Gliomas.a 
Postmortem Study of 25 Cases. Cancer (1979) 44:1256-72. doi: 10.1002/ 1097-0142(197910)44:4<1256::AID-CNCR2820440415>3.0.CO;2-T

48. Constanzo J, Dumont M, Lebel R, Tremblay L, Whittingstall K, MassonCôté L, et al. Diffusion MRI Monitoring of Specific Structures in the Irradiated Rat Brain. Magnet Resonance Med (2018) 80:1614-25. doi: $10.1002 / \mathrm{mrm} .27112$

49. Nagasawa H, Little JB. Induction of Sister Chromatid Exchanges by Extremely Low Doses of $\alpha$-Particles. Cancer Res (1992) 52:6394-6.

50. Zhou H, Randers-Pehrson G, Waldren CA, Vannais D, Hall EJ, Hei TK. Induction of a Bystander Mutagenic Effect of Alpha Particles in Mammalian Cells. PNAS (2000) 97:2099-104. doi: 10.1073/pnas.030420797

51. Azzam EI, De Toledo SM, Spitz DR, Little JB. Oxidative Metabolism Modulates Signal Transduction and Micronucleus Formation in Bystander Cells From Alpha-Particle-Irradiated Normal Human Fibroblast Cultures. Cancer Res (2002) 62:5436-42.

52. Azzam EI, de Toledo SM, Gooding T, Little JB. Intercellular Communication is Involved in the Bystander Regulation of Gene Expression in Human Cells Exposed to Very Low Fluences of Alpha Particles. Radiat Res (1998) 150:497-504. doi: 10.2307/3579865

53. Azzam EI, de Toledo SM, Little JB. Direct Evidence for the Participation of Gap Junction-Mediated Intercellular Communication in the Transmission of Damage Signals From $\alpha$-Particle Irradiated to Nonirradiated Cells. Proc Natl Acad Sci USA (2001) 98:473-8. doi: 10.1073/pnas.98.2.473

54. Higgins JP, Bernstein MB, Hodge JW. Enhancing Immune Responses to Tumor-Associated Antigens. Cancer Biol Ther (2009) 8:1440-9. doi: 10.4161/cbt.8.15.9133

55. Gannagé M, Buzyn A, Bogiatzi SI, Lambert M, Soumelis V, Dal Cortivo L, et al. Induction of NKG2D Ligands by Gamma Radiation and Tumor Necrosis Factor-Alpha may Participate in the Tissue Damage During Acute Graft-Versus-Host Disease. Transplantation (2008) 85:911-5. doi: 10.1097/TP.0b013e31816691ef

56. Krombach J, Hennel R, Brix N, Orth M, Schoetz U, Ernst A, et al. Priming Anti-Tumor Immunity by Radiotherapy: Dying Tumor Cell-Derived DAMPs Trigger Endothelial Cell Activation and Recruitment of Myeloid Cells. Oncoimmunology (2018) 8:e1523097. doi: 10.1080/2162402X. 2018.1523097

57. Lim JYH, Gerber SA, Murphy SP, Lord EM. Type I Interferons Induced by Radiation Therapy Mediate Recruitment and Effector Function of CD8+ T Cells. Cancer Immunol Immunother (2014) 63:259-71. doi: 10.1007/s00262013-1506-7

58. Galluzzi L, Vitale I, Warren S, Adjemian S, Agostinis P, Martinez AB, et al. Consensus Guidelines for the Definition, Detection and Interpretation of Immunogenic Cell Death. J Immunother Cancer (2020) 8:e000337. doi: 10.1136/jitc-2019-000337

59. Krysko DV, Garg AD, Kaczmarek A, Krysko O, Agostinis P, Vandenabeele P. Immunogenic Cell Death and DAMPs in Cancer Therapy. Nat Rev Cancer (2012) 12:860-75. doi: 10.1038/nrc3380

60. Ghiringhelli F, Apetoh L, Tesniere A, Aymeric L, Ma Y, Ortiz C, et al. Activation of the NLRP3 Inflammasome in Dendritic Cells Induces IL-1 $\beta$ Dependent Adaptive Immunity Against Tumors. Nat Med (2009) 15:11708. doi: $10.1038 / \mathrm{nm} .2028$

61. Pisetsky DS. The Origin and Properties of Extracellular Dna: From PAMP to DAMP. Clin Immunol (2012) 144:32-40. doi: 10.1016/ j.clim.2012.04.006

62. Yang H, Hreggvidsdottir HS, Palmblad K, Wang H, Ochani M, Li J, et al. A Critical Cysteine is Required for HMGB1 Binding to Toll-like Receptor 4 and Activation of Macrophage Cytokine Release. Proc Natl Acad Sci USA (2010) 107:11942-7. doi: 10.1073/pnas.1003893107

63. Panaretakis T, Joza N, Modjtahedi N, Tesniere A, Vitale I, Durchschlag M, et al. The Co-Translocation of ERp57 and Calreticulin Determines the Immunogenicity of Cell Death. Cell Death Differ (2008) 15:1499-509. doi: 10.1038/cdd.2008.67

64. Pouget J-P, Georgakilas AG, Ravanat J-L. Targeted and Off-Target (Bystander and Abscopal) Effects of Radiation Therapy: Redox Mechanisms and Risk-Benefit Analysis. Antioxid Redox Signaling (2018). doi: 10.1089 /ars.2017.7267

65. Apetoh L, Ghiringhelli F, Tesniere A, Obeid M, Ortiz C, Criollo A, et al. TollLike Receptor 4-Dependent Contribution of the Immune System to
Anticancer Chemotherapy and Radiotherapy. Nat Med (2007) 13:1050-9. doi: $10.1038 / \mathrm{nm} 1622$

66. Naeim F, Nagesh Rao P, Song SX, Phan RT. Chapter 7 - Bone Marrow Aplasia. In: Naeim F, Nagesh Rao P, Song SX, Phan RT, editors. Atlas of Hematopathology, 2nd ed. Academic Press (2018). p. 129-43. doi: 10.1016/ B978-0-12-809843-1.00007-3

67. Abbatt J, Lea AJ. The Incidence of Leukaemia in Ankylosing Spondylitis Treated With X Rays. Lancet (1956) 268:1317-20. doi: 10.1016/S0140-6736 (56) $91481-7$

68. Berk PD, Goldberg JD, Silverstein MN, Weinfeld A, Donovan PB, Ellis JT, et al. Increased Incidence of Acute Leukemia in Polycythemia Vera Associated With Chlorambucil Therapy. New Engl J Med (1981) 304:4417. doi: $10.1056 / \mathrm{NEJM} 198102193040801$

69. Levine EG, Bloomfield CD. Leukemias and Myelodysplastic Syndromes Secondary to Drug, Radiation, and Environmental Exposure. Semin Oncol (1992) 19:47-84.

70. Carter SL, Eklund AC, Kohane IS, Harris LN, Szallasi Z. A Signature of Chromosomal Instability Inferred From Gene Expression Profiles Predicts Clinical Outcome in Multiple Human Cancers. Nat Genet (2006) 38:1043-8. doi: $10.1038 / \mathrm{ng} 1861$

71. Kabacik S, Mackay A, Tamber N, Manning G, Finnon P, Paillier F, et al. Gene Expression Following Ionising Radiation: Identification of Biomarkers for Dose Estimation and Prediction of Individual Response. Int J Radiat Biol (2011) 87:115-29. doi: 10.3109/09553002.2010.519424

72. Chen DS, Mellman I. Elements of Cancer Immunity and the CancerImmune Set Point. Nature (2017) 541:321-30. doi: 10.1038/nature21349

73. Candéias SM, Testard I. The Many Interactions Between the Innate Immune System and the Response to Radiation. Cancer Lett (2015) 368:173-8. doi: 10.1016/j.canlet.2015.02.007

74. Manning G, Kabacik S, Finnon P, Bouffler S, Badie C. High and Low Dose Responses of Transcriptional Biomarkers in Ex Vivo X-irradiated Human Blood. Int J Radiat Biol (2013) 89:512-22. doi: 10.3109/09553002.2013.769694

75. El-Saghire H, Thierens H, Monsieurs P, Michaux A, Vandevoorde C, Baatout S. Gene Set Enrichment Analysis Highlights Different Gene Expression Profiles in Whole Blood Samples X-irradiated With Low and High Doses. Int J Radiat Biol (2013) 89:628-38. doi: 10.3109/ 09553002.2013.782448

76. Christmann M, Kaina B. Transcriptional Regulation of Human DNA Repair Genes Following Genotoxic Stress: Trigger Mechanisms, Inducible Responses and Genotoxic Adaptation. Nucleic Acids Res (2013) 41:840320. doi: $10.1093 /$ nar/gkt635

77. O'Brien G, Cruz-Garcia L, Majewski M, Grepl J, Abend M, Port M, et al. FDXR is a Biomarker of Radiation Exposure In Vivo. Sci Rep (2018) 8:684. doi: 10.1038/s41598-017-19043-w

78. Balázs K, Kis E, Badie C, Bogdándi EN, Candéias S, Garcia LC, et al. Radiotherapy-Induced Changes in the Systemic Immune and Inflammation Parameters of Head and Neck Cancer Patients. Cancers (Basel) (2019) 11 (9):1324. doi: 10.3390/cancers11091324

79. Bouquet F, Pal A, Pilones KA, Demaria S, Hann B, Akhurst RJ, et al. Tgf $\beta 1$ Inhibition Increases the Radiosensitivity of Breast Cancer Cells in Vitro and Promotes Tumor Control by Radiation In Vivo. Clin Cancer Res (2011) 17:6754-65. doi: 10.1158/1078-0432.CCR-11-0544

80. Vanpouille-Box C, Diamond JM, Pilones KA, Zavadil J, Babb JS, Formenti SC, et al. Tgf $\beta$ Is a Master Regulator of Radiation Therapy-Induced Antitumor Immunity. Cancer Res (2015) 75:2232-42. doi: 10.1158/0008-5472.CAN-14-3511

81. Favaudon V, Caplier L, Monceau V, Pouzoulet F, Sayarath M, Fouillade C, et al. Ultrahigh Dose-Rate FLASH Irradiation Increases the Differential Response Between Normal and Tumor Tissue in Mice. Sci Trans Med (2014) 6:245ra93-245ra93. doi: 10.1126/scitranslmed.3008973

82. Muroyama Y, Nirschl TR, Kochel CM, Lopez-Bujanda Z, Theodros D, Mao W, et al. Stereotactic Radiotherapy Increases Functionally Suppressive Regulatory T Cells in the Tumor Microenvironment. Cancer Immunol Res (2017) 5:992-1004. doi: 10.1158/2326-6066.CIR-17-0040

83. Schoenhals JE, Cushman TR, Barsoumian HB, Li A, Cadena AP, Niknam S, et al. Anti-Glucocorticoid-Induced Tumor Necrosis Factor-Related Protein (Gitr) Therapy Overcomes Radiation-Induced Treg Immunosuppression and Drives Abscopal Effects. Front Immunol (2018) 9:2170. doi: 10.3389/ fimmu.2018.02170 
84. Kang J, Demaria S, Formenti S. Current Clinical Trials Testing the Combination of Immunotherapy With Radiotherapy. I Immunother Cancer (2016) 4:51. doi: 10.1186/s40425-016-0156-7

85. Pinto AT, Pinto ML, Cardoso AP, Monteiro C, Pinto MT, Maia AF, et al. Ionizing Radiation Modulates Human Macrophages Towards a ProInflammatory Phenotype Preserving Their Pro-Invasive and ProAngiogenic Capacities. Sci Rep (2016) 6:18765. doi: 10.1038/srep18765

86. Mikhalkevich N, O'Carroll IP, Tkavc R, Lund K, Sukumar G, Dalgard CL, et al. Response of Human Macrophages to Gamma Radiation is Mediated Via Expression of Endogenous Retroviruses. PloS Pathog (2021) 17:18765e1009305. doi: 10.1371/journal.ppat.1009305

87. Klug F, Prakash H, Huber PE, Seibel T, Bender N, Halama N, et al. LowDose Irradiation Programs Macrophage Differentiation to an Inost/M1 Phenotype That Orchestrates Effective T Cell Immunotherapy. Cancer Cell (2013) 24:589-602. doi: 10.1016/j.ccr.2013.09.014

88. Wu Q, Allouch A, Paoletti A, Leteur C, Mirjolet C, Martins I, et al. NOX2Dependent ATM Kinase Activation Dictates Pro-Inflammatory Macrophage Phenotype and Improves Effectiveness to Radiation Therapy. Cell Death Differ (2017) 24:1632-44. doi: 10.1038/cdd.2017.91

89. Chen X, Fu E, Lou H, Mao X, Yan B, Tong F, et al. IL-6 Induced M1 Type Macrophage Polarization Increases Radiosensitivity in HPV Positive Head and Neck Cancer. Cancer Lett (2019) 456:69-79. doi: 10.1016/ j.canlet.2019.04.032

90. Rahal OM, Wolfe AR, Mandal PK, Larson R, Tin S, Jimenez C, et al. Blocking Interleukin (IL)4- and IL13-Mediated Phosphorylation of STAT6 (Tyr641) Decreases M2 Polarization of Macrophages and Protects Against Macrophage-Mediated Radioresistance of Inflammatory Breast Cancer. Int $J$ Radiat Oncol Biol Phys (2018) 100:1034-43. doi: 10.1016/j.ijrobp.2017. 11.043

91. Pandey R, Shankar BS, Sharma D, Sainis DKB. Low Dose Radiation Induced Immunomodulation: Effect on Macrophages and CD8+ T Cells. Int J Radiat Biol (2005) 81:801-12. doi: 10.1080/09553000500531886

92. Wunderlich R, Rühle PF, Deloch L, Rödel F, Fietkau R, Gaipl US, et al. Ionizing Radiation Reduces the Capacity of Activated Macrophages to Induce T-cell Proliferation, But Does Not Trigger Dendritic Cell-Mediated non-Targeted Effects. Int J Radiat Biol (2019) 95:33-43. doi: 10.1080/ 09553002.2018.1490037

93. Jones KI, Tiersma J, Yuzhalin AE, Gordon-Weeks AN, Buzzelli J, Im JH, et al. Radiation Combined With Macrophage Depletion Promotes Adaptive Immunity and Potentiates Checkpoint Blockade. EMBO Mol Med (2018) 10: e9342. doi: 10.15252/emmm.201809342

94. Tsai C-S, Chen F-H, Wang C-C, Huang H-L, Jung S-M, Wu C-J, et al. Macrophages From Irradiated Tumors Express Higher Levels of Inos, Arginase-I and COX-2, and Promote Tumor Growth. Int J Radiat Oncol Biol Phys (2007) 68:499-507. doi: 10.1016/j.ijrobp.2007.01.041

95. Balermpas P, Rödel F, Liberz R, Oppermann J, Wagenblast J, Ghanaati S, et al. Head and Neck Cancer Relapse After Chemoradiotherapy Correlates With CD163+ Macrophages in Primary Tumour and CD11b+ Myeloid Cells in Recurrences. Br J Cancer (2014) 111:1509-18. doi: 10.1038/bjc.2014.446

96. Loinard C, Vilar J, Milliat F, Lévy B, Benderitter M. Monocytes/ Macrophages Mobilization Orchestrate Neovascularization After Localized Colorectal Irradiation. Radiat Res (2017) 187:549-61. doi: 10.1667/ RR14398.1

97. Ghita M, Dunne VL, McMahon SJ, Osman SO, Small DM, Weldon S, et al. Preclinical Evaluation of Dose-Volume Effects and Lung Toxicity Occurring in and Out-of-Field. Int J Radiat Oncol Biol Phys (2019) 103:1231-40. doi: 10.1016/j.jijobp.2018.12.010

98. Abernathy LM, Fountain MD, Rothstein SE, David JM, Yunker CK, Rakowski J, et al. Soy Isoflavones Promote Radioprotection of Normal Lung Tissue by Inhibition of Radiation-Induced Activation of Macrophages and Neutrophils. J Thorac Oncol (2015) 10:1703-12. doi: 10.1097/JTO. 0000000000000677

99. Yu H-H, Chengchuan KOE, Chang C-L, Yuan KS-P, Wu ATH, Shan Y-S, et al. Fucoidan Inhibits Radiation-Induced Pneumonitis and Lung Fibrosis by Reducing Inflammatory Cytokine Expression in Lung Tissues. Mar Drugs (2018) 16(10):392. doi: 10.3390/md16100392

100. Dadrich M, Nicolay NH, Flechsig P, Bickelhaupt S, Hoeltgen L, Roeder F, et al. Combined Inhibition of Tgf $\beta$ and PDGF Signaling Attenuates
Radiation-Induced Pulmonary Fibrosis. Oncoimmunology (2015) 5(5): e1123366. doi: 10.1080/2162402X.2015.1123366

101. Bickelhaupt S, Erbel C, Timke C, Wirkner U, Dadrich M, Flechsig P, et al. Effects of CTGF Blockade on Attenuation and Reversal of Radiation-Induced Pulmonary Fibrosis. JNCI: J Natl Cancer Inst (2017) 109:8. doi: 10.1093/jnci/ djw339

102. Sternlicht MD, Wirkner U, Bickelhaupt S, Lopez Perez R, Tietz A, Lipson KE, et al. Radiation-Induced Pulmonary Gene Expression Changes are Attenuated by the CTGF Antibody Pamrevlumab. Respir Res (2018) 19 (1):14. doi: 10.1186/s12931-018-0720-4

103. Stansborough RL, Bateman EH, Al-Dasooqi N, Bowen JM, Wignall A, Keefe DM, et al. Vascular Endothelial Growth Factor (VEGF), Transforming Growth Factor Beta ( $\operatorname{Tgf} \beta)$, Angiostatin, and Endostatin are Increased in Radiotherapy-Induced Gastrointestinal Toxicity. Int J Radiat Biol (2018) 94:645-55. doi: 10.1080/09553002. 2018.1483588

104. Baselet B, Sonveaux P, Baatout S, Aerts A. Pathological Effects of Ionizing Radiation: Endothelial Activation and Dysfunction. Cell Mol Life Sci (2019) 76:699-728. doi: 10.1007/s00018-018-2956-z

105. Torok JA, Oh P, Castle KD, Reinsvold M, Ma Y, Luo L, et al. Deletion of Atm in Tumor But Not Endothelial Cells Improves Radiation Response in a Primary Mouse Model of Lung Adenocarcinoma. Cancer Res (2019) 79:77382. doi: 10.1158/0008-5472.CAN-17-3103

106. Zhang Q, Green MD, Lang X, Lazarus J, Parsels JD, Wei S, et al. Inhibition of ATM Increases Interferon Signaling and Sensitizes Pancreatic Cancer to Immune Checkpoint Blockade Therapy. Cancer Res (2019) 79:3940-51. doi: 10.1158/0008-5472.CAN-19-0761

107. Palayoor ST, John-Aryankalayil M, Makinde AY, Falduto MT, Magnuson SR, Coleman CN. Differential Expression of Stress and Immune Response Pathway Transcripts and miRNAs in Normal Human Endothelial Cells Subjected to Fractionated or Single-Dose Radiation. Mol Cancer Res (2014) 12:1002-15. doi: 10.1158/1541-7786.MCR-13-0623

108. Hildebrandt G, Maggiorella L, Rödel F, Rödel V, Willis D, Trott K-R. Mononuclear Cell Adhesion and Cell Adhesion Molecule Liberation After X-Irradiation of Activated Endothelial Cells In Vitro. Int J Radiat Biol (2002) 78:315-25. doi: 10.1080/09553000110106027

109. Kouam PN, Rezniczek GA, Adamietz IA, Bühler H. Ionizing Radiation Increases the Endothelial Permeability and the Transendothelial Migration of Tumor Cells Through ADAM10-activation and Subsequent Degradation of VE-Cadherin. BMC Cancer (2019) 19(1):958. doi: 10.1186/s12885-0196219-7

110. Korpela E, Liu SK. Endothelial Perturbations and Therapeutic Strategies in Normal Tissue Radiation Damage. Radiat Oncol (2014) 9:266. doi: 10.1186/ s13014-014-0266-7

111. Stewart FA, Seemann I, Hoving S, Russell NS. Understanding RadiationInduced Cardiovascular Damage and Strategies for Intervention. Clin Oncol (2013) 25:617-24. doi: 10.1016/j.clon.2013.06.012

112. Rannou E, François A, Toullec A, Guipaud O, Buard V, Tarlet G, et al. In Vivo Evidence for an Endothelium-Dependent Mechanism in RadiationInduced Normal Tissue Injury. Sci Rep (2015) 5:15738. doi: 10.1038/ srep 15738

113. Wiesemann A, Ketteler J, Slama A, Wirsdörfer F, Hager T, Röck K, et al. Inhibition of Radiation-Induced Ccl2 Signaling Protects Lungs From Vascular Dysfunction and Endothelial Cell Loss. Antioxid Redox Signaling (2018) 30:213-31. doi: 10.1089/ars.2017.7458

114. Gorchs L, Hellevik T, Bruun J-A, Camilio K-A, Al-Saad S, Stuge T-B, et al. Cancer-Associated Fibroblasts From Lung Tumors Maintain Their Immunosuppressive Abilities After High-Dose Irradiation. Front Oncol (2015) 5:87. doi: 10.3389/fonc.2015.00087

115. Tommelein J, Vlieghere ED, Verset L, Melsens E, Leenders J, Descamps B, et al. Radiotherapy-Activated Cancer-Associated Fibroblasts Promote Tumor Progression Through Paracrine IGF-1R Activation. Cancer Res (2017) 78(3):659-70. doi: 10.1158/0008-5472.CAN-17-0524

116. Piper M, Mueller AC, Karam SD. The Interplay Between Cancer Associated Fibroblasts and Immune Cells in the Context of Radiation Therapy. Mol Carcinog (2020) 59:754-65. doi: 10.1002/mc.23205

117. Berzaghi R, Ahktar MA, Islam A, Pedersen BD, Hellevik T, MartinezZubiaurre I. Fibroblast-Mediated Immunoregulation of Macrophage 
Function Is Maintained After Irradiation. Cancers (Basel) (2019) 11(5):689. doi: 10.3390/cancers 11050689

118. Pereira PMR, Edwards KJ, Mandleywala K, Carter LM, Escorcia FE, Campesato LF, et al. Inos Regulates the Therapeutic Response of Pancreatic Cancer Cells to Radiotherapy. Cancer Res (2020) 80:1681-92. doi: 10.1158/0008-5472.CAN-19-2991

119. Li D, Qu C, Ning Z, Wang H, Zang K, Zhuang L, et al. Radiation Promotes Epithelial-to-Mesenchymal Transition and Invasion of Pancreatic Cancer Cell by Activating Carcinoma-Associated Fibroblasts. Am J Cancer Res (2016) 6:2192-206.

120. Ebbing EA, van der Zalm AP, Steins A, Creemers A, Hermsen S, Rentenaar $\mathrm{R}$, et al. Stromal-Derived Interleukin 6 Drives Epithelial-to-Mesenchymal Transition and Therapy Resistance in Esophageal Adenocarcinoma. Proc Natl Acad Sci USA (2019) 116:2237-42. doi: 10.1073/pnas.1820459116

121. Rødningen OK, Overgaard J, Alsner J, Hastie T, Børresen-Dale A-L. Microarray Analysis of the Transcriptional Response to Single or Multiple Doses of Ionizing Radiation in Human Subcutaneous Fibroblasts. Radiother Oncol (2005) 77:231-40. doi: 10.1016/j.radonc.2005.09.020

122. Miles FL, Sikes RA. Insidious Changes in Stromal Matrix Fuel Cancer Progression. Mol Cancer Res (2014) 12:297-312. doi: 10.1158/15417786.MCR-13-0535

123. Zanoni M, Cortesi M, Zamagni A, Tesei A. The Role of Mesenchymal Stem Cells in Radiation-Induced Lung Fibrosis. Int J Mol Sci (2019) 20:3876. doi: 10.3390/ijms20163876

124. Klein D, Schmetter A, Imsak R, Wirsdörfer F, Unger K, Jastrow H, et al. Therapy With Multipotent Mesenchymal Stromal Cells Protects Lungs From Radiation-Induced Injury and Reduces the Risk of Lung Metastasis. Antioxid Redox Signal (2016) 24:53-69. doi: 10.1089/ars.2014.6183

125. Kim SM, Oh JH, Park SA, Ryu CH, Lim JY, Kim D-S, et al. Irradiation Enhances the Tumor Tropism and Therapeutic Potential of Tumor Necrosis Factor-Related Apoptosis-Inducing Ligand-Secreting Human Umbilical Cord Blood-Derived Mesenchymal Stem Cells in Glioma Therapy. Stem Cells (2010) 28:2217-28. doi: 10.1002/stem.543

126. Tao X, Sun M, Chen M, Ying R, Su W, Zhang J, et al. HMGB1-Modified Mesenchymal Stem Cells Attenuate Radiation-Induced Vascular Injury Possibly Via Their High Motility and Facilitation of Endothelial Differentiation. Stem Cell Res Ther (2019) 10:92. doi: 10.1186/s13287-019$1197-\mathrm{x}$

127. Klein D, Steens J, Wiesemann A, Schulz F, Kaschani F, Röck K, et al. Mesenchymal Stem Cell Therapy Protects Lungs From Radiation-Induced Endothelial Cell Loss by Restoring Superoxide Dismutase 1 Expression. Antioxid Redox Signal (2017) 26:563-82. doi: 10.1089/ars.2016.6748

128. Dong L-H, Jiang Y-Y, Liu Y-J, Cui S, Xia C-C, Qu C, et al. The Anti-Fibrotic Effects of Mesenchymal Stem Cells on Irradiated Lungs Via Stimulating Endogenous Secretion of HGF and PGE2. Sci Rep (2015) 5:8713. doi: $10.1038 /$ srep 08713

129. de Araujo Farias V, O’Valle F, Serrano-Saenz S, Anderson P, Andrés E, López-Peñalver J, et al. Exosomes Derived From Mesenchymal Stem Cells Enhance Radiotherapy-Induced Cell Death in Tumor and Metastatic Tumor Foci. Mol Cancer (2018) 17:122. doi: 10.1186/s12943-018-0867-0

130. Iurescia S, Fioretti D, Rinaldi M. Targeting Cytosolic Nucleic Acid-Sensing Pathways for Cancer Immunotherapies. Front Immunol (2018) 9:711. doi: 10.3389/fimmu.2018.00711

131. Sun L, Wu J, Du F, Chen X, Chen ZJ. Cyclic GMP-AMP Synthase is a Cytosolic DNA Sensor That Activates the Type I Interferon Pathway. Science (2013) 339:786-91. doi: 10.1126/science.1232458

132. Wu J, Sun L, Chen X, Du F, Shi H, Chen C, et al. Cyclic GMP-AMP is an Endogenous Second Messenger in Innate Immune Signaling by Cytosolic Dna. Science (2013) 339:826-30. doi: 10.1126/science.1229963

133. Ablasser A, Chen ZJ. cGAS in Action: Expanding Roles in Immunity and Inflammation. Science (2019) 363(6431):eeaat8657. doi: 10.1126/science. aat 8657

134. Wu Y, Wu X, Wu L, Wang X, Liu Z. The Anticancer Functions of RIG-I-like Receptors, RIG-I and MDA5, and Their Applications in Cancer Therapy. Transl Res (2017) 190:51-60. doi: 10.1016/j.trsl.2017.08.004

135. Durante M, Formenti SC. Radiation-Induced Chromosomal Aberrations and Immunotherapy: Micronuclei, Cytosolic DNA, and Interferon-Production Pathway. Front Oncol (2018) 8:192. doi: 10.3389/fonc.2018.00192
136. Müller W-U, Nüsse M, Miller BM, Slavotinek A, Viaggi S, Streffer C. Micronuclei: A Biological Indicator of Radiation Damage. Mutat Res Rev Genet Toxicol (1996) 366:163-9. doi: 10.1016/S0165-1110(96)90037-8

137. Hintzsche H, Hemmann U, Poth A, Utesch D, Lott J, Stopper H. Working Group "In Vitro Micronucleus Test”, Gesellschaft Für UmweltMutationsforschung (Gum, German-speaking Section of the European Environmental Mutagenesis and Genomics Society EEMGS). Fate of Micronuclei and Micronucleated Cells. Mutat Res (2017) 771:85-98. doi: 10.1016/j.mrrev.2017.02.002

138. Hatch EM, Fischer AH, Deerinck TJ, Hetzer MW. Catastrophic Nuclear Envelope Collapse in Cancer Cell Micronuclei. Cell (2013) 154:47-60. doi: 10.1016/j.cell.2013.06.007

139. Ainsbury EA, Bakhanova E, Barquinero JF, Brai M, Chumak V, Correcher V, et al. Review of Retrospective Dosimetry Techniques for External Ionising Radiation Exposures. Radiat Prot Dosimetry (2011) 147:573-92. doi: 10.1093/rpd/ncq499

140. Piron B, Paillas S, Boudousq V, Pèlegrin A, Bascoul-Mollevi C, Chouin N, et al. DNA Damage-Centered Signaling Pathways are Effectively Activated During Low Dose-Rate Auger Radioimmunotherapy. Nucl Med Biol (2014) 41:e75-83. doi: 10.1016/j.nucmedbio.2014.01.012

141. Mackenzie KJ, Carroll P, Martin C-A, Murina O, Fluteau A, Simpson D, et al. cGAS Surveillance of Micronuclei Links Genome Instability to Innate Immunity. Nature (2017) 548:461-5. doi: 10.1038/nature23449

142. Harding SM, Benci JL, Irianto J, Discher DE, Minn AJ, Greenberg RA. Mitotic Progression Following DNA Damage Enables Pattern Recognition Within Micronuclei. Nature (2017) 548:466-70. doi: 10.1038/nature23470

143. Vanpouille-Box C, Alard A, Aryankalayil MJ, Sarfraz Y, Diamond JM, Schneider RJ, et al. DNA Exonuclease Trex1 Regulates RadiotherapyInduced Tumour Immunogenicity. Nat Commun (2017) 8:15618. doi: $10.1038 /$ ncomms 15618

144. Kitai Y, Kawasaki T, Sueyoshi T, Kobiyama K, Ishii KJ, Zou J, et al. DnaContaining Exosomes Derived From Cancer Cells Treated With Topotecan Activate a STING-Dependent Pathway and Reinforce Antitumor Immunity. J Immunol (2017) 198:1649-59. doi: 10.4049/jimmunol.1601694

145. Diamond JM, Vanpouille-Box C, Spada S, Rudqvist N-P, Chapman JR, Ueberheide BM, et al. Exosomes Shuttle Trex1-Sensitive IFN-Stimulatory dsDNA From Irradiated Cancer Cells to Dcs. Cancer Immunol Res (2018) 6:910-20. doi: 10.1158/2326-6066.CIR-17-0581

146. Vanpouille-Box C, Pilones KA, Wennerberg E, Formenti SC, Demaria S. In Situ Vaccination by Radiotherapy to Improve Responses to anti-CTLA-4 Treatment. Vaccine (2015) 33:7415-22. doi: 10.1016/j.vaccine.2015.05.105

147. Stetson DB, Ko JS, Heidmann T, Medzhitov R. Trex1 Prevents Cell-Intrinsic Initiation of Autoimmunity. Cell (2008) 134:587-98. doi: 10.1016/ j.cell.2008.06.032

148. Vanpouille-Box C, Formenti SC, Demaria S. TREX1 Dictates the Immune Fate of Irradiated Cancer Cells. Oncoimmunology (2017) 8:15618. doi: 10.1080/2162402X.2017.1339857

149. White MJ, McArthur K, Metcalf D, Lane RM, Cambier JC, Herold MJ, et al. Apoptotic Caspases Suppress Mtdna-Induced STING-mediated Type I IFN Production. Cell (2014) 159:1549-62. doi: 10.1016/j.cell.2014.11.036

150. Rongvaux A, Jackson R, Harman CCD, Li T, West AP, de Zoete MR, et al. Apoptotic Caspases Prevent the Induction of Type I Interferons by Mitochondrial DNA. Cell (2014) 159:1563-77. doi: 10.1016/j.cell.2014.11.037

151. Xu MM, Pu Y, Han D, Shi Y, Cao X, Liang H, et al. Dendritic Cells But Not Macrophages Sense Tumor Mitochondrial DNA for Cross-priming Through Signal Regulatory Protein $\alpha$ Signaling. Immunity (2017) 47:363-373.e5. doi: 10.1016/j.immuni.2017.07.016

152. Kam WW-Y, Banati RB. Effects of Ionizing Radiation on Mitochondria. Free Radical Biol Med (2013) 65:607-19. doi: 10.1016/j.freeradbiomed. 2013.07.024

153. Prise KM, O'Sullivan JM. Radiation-Induced Bystander Signalling in Cancer Therapy. Nat Rev Cancer (2009) 9:351-60. doi: 10.1038/nrc2603

154. Yang G, Wu L, Chen S, Zhu L, Huang P, Tong L, et al. Mitochondrial Dysfunction Resulting From Loss of Cytochrome C Impairs RadiationInduced Bystander Effect. Br J Cancer (2009) 100:1912-6. doi: 10.1038/ sj.bjc. 6605087

155. Friedland W, Schmitt E, Kundrát P, Baiocco G, Ottolenghi A. TrackStructure Simulations of Energy Deposition Patterns to Mitochondria and 
Damage to Their DNA. Int J Radiat Biol (2019) 95:3-11. doi: 10.1080/ 09553002.2018.1450532

156. Deng L, Liang H, Xu M, Yang X, Burnette B, Arina A, et al. STINGDependent Cytosolic Dna Sensing Promotes Radiation-induced Type I Interferon-Dependent Antitumor Immunity in Immunogenic Tumors. Immunity (2014) 41:843-52. doi: 10.1016/j.immuni.2014.10.019

157. Liu Y, Crowe WN, Wang L, Lu Y, Petty WJ, Habib AA, et al. An Inhalable Nanoparticulate STING Agonist Synergizes With Radiotherapy to Confer Long-Term Control of Lung Metastases. Nat Commun (2019) 10:5108. doi: 10.1038/s41467-019-13094-5

158. Ablasser A, Schmid-Burgk JL, Hemmerling I, Horvath GL, Schmidt T, Latz E, et al. Cell Intrinsic Immunity Spreads to Bystander Cells Via the Intercellular Transfer of Cgamp. Nature (2013) 503:530-4. doi: 10.1038/ nature 12640

159. Chen Q, Boire A, Jin X, Valiente M, Er EE, Lopez-Soto A, et al. CarcinomaAstrocyte Gap Junctions Promote Brain Metastasis by cGAMP Transfer. Nature (2016) 533:493-8. doi: 10.1038/nature18268

160. Schadt L, Sparano C, Schweiger NA, Silina K, Cecconi V, Lucchiari G, et al. Cancer-Cell-Intrinsic Cgas Expression Mediates Tumor Immunogenicity. Cell Rep (2019) 29:1236-48.e7. doi: 10.1016/j.celrep.2019.09.065

161. Pépin G, Nardo DD, Rootes CL, Ullah TR, Al-Asmari SS, Balka KR, et al. Connexin-Dependent Transfer of cGAMP to Phagocytes Modulates Antiviral Responses. mBio (2020) 11(1):e03187-19. doi: 10.1128/mBio.03187-19

162. Marcus A, Mao AJ, Lensink-Vasan M, Wang L, Vance RE, Raulet DH. Tumor-Derived Cgamp Triggers a STING-Mediated Interferon Response in Non-tumor Cells to Activate the NK Cell Response. Immunity (2018) 49:754-63.e4. doi: 10.1016/j.immuni.2018.09.016

163. Tkach M, Théry C. Communication by Extracellular Vesicles: Where We Are and Where We Need to Go. Cell (2016) 164:1226-32. doi: 10.1016/ j.cell.2016.01.043

164. Bakhoum SF, Ngo B, Laughney AM, Cavallo J-A, Murphy CJ, Ly P, et al. Chromosomal Instability Drives Metastasis Through a Cytosolic DNA Response. Nature (2018) 553:467-72. doi: 10.1038/nature25432

165. Gros L, Urcino C, Constanzo J, Zangger N, Meylan E, Bonnefoy N, et al. Low STING Expression in a Transplantable KrasG12D/P53ko Lung Cancer Model Contributes to SiglecF+ Neutrophil and CD103+Treg Accumulation in Tumors. bioRxiv (2021). doi: 10.1101/2021.01.04.425311 2021.01.04.425311.

166. Mladenov E, Fan X, Dueva R, Soni A. Iliakis G. Radiation-Dose-Dependent Functional Synergisms Between ATM, ATR and DNA-PKcs in Checkpoint Control and Resection in G 2 -Phase. Sci Rep (2019) 9:8255. doi: 10.1038/ s41598-019-44771-6

167. Gewirtz DA, Holt SE, Elmore LW. Accelerated Senescence: An Emerging Role in Tumor Cell Response to Chemotherapy and Radiation. Biochem Pharmacol (2008) 76:947-57. doi: 10.1016/j.bcp.2008.06.024

168. Wang Z, Gao J, Liu H, Ohno Y, Xu C. Targeting Senescent Cells and Tumor Therapy (Review). Int J Mol Med (2020) 46:1603-10. doi: 10.3892/ ijmm.2020.4705

169. Wang B, Kohli J, Demaria M. Senescent Cells in Cancer Therapy: Friends or Foes? Trends Cancer (2020) 6:838-57. doi: 10.1016/j.trecan.2020.05.004

170. Faget DV, Ren Q, Stewart SA. Unmasking Senescence: Context-Dependent Effects of SASP in Cancer. Nat Rev Cancer (2019) 19:439-53. doi: 10.1038/ s41568-019-0156-2

171. Kansara M, Leong HS, Lin DM, Popkiss S, Pang P, Garsed DW, et al. Immune Response to RB1-Regulated Senescence Limits Radiation-Induced Osteosarcoma Formation. J Clin Invest (2013) 123:5351-60. doi: 10.1172/ JCI70559

172. Fielding CA, McLoughlin RM, McLeod L, Colmont CS, Najdovska M, Grail D, et al. IL-6 Regulates Neutrophil Trafficking During Acute Inflammation Via STAT3. J Immunol (2008) 181:2189-95. doi: 10.4049/jimmunol.181.3.2189

173. Faunce DE, Sonoda K-H, Stein-Streilein J. Mip-2 Recruits Nkt Cells to the Spleen During Tolerance Induction. J Immunol (2001) 166:313-21. doi: 10.4049/jimmunol.166.1.313
174. Swann JB, Uldrich AP, van Dommelen S, Sharkey J, Murray WK, Godfrey DI, et al. Type I Natural Killer T Cells Suppress Tumors Caused by p53 Loss in Mice. Blood (2009) 113:6382-5. doi: 10.1182/blood-2009-01-198564

175. Deshayes E, Roumiguie M, Thibault C, Beuzeboc P, Cachin F, Hennequin C, et al. Radium 223 Dichloride for Prostate Cancer Treatment. Drug Des Devel Ther (2017) 11:2643-51. doi: 10.2147/DDDT.S122417

176. Dou Z, Ghosh K, Vizioli MG, Zhu J, Sen P, Wangensteen KJ, et al. Cytoplasmic Chromatin Triggers Inflammation in Senescence and Cancer. Nature (2017) 550:402-6. doi: 10.1038/nature24050

177. Takahashi A, Loo TM, Okada R, Kamachi F, Watanabe Y, Wakita M, et al. Downregulation of Cytoplasmic DNases Is Implicated in Cytoplasmic DNA Accumulation and SASP in Senescent Cells. Nat Commun (2018) 9:1-12. doi: 10.1038/s41467-018-03555-8

178. Kondo T, Kobayashi J, Saitoh T, Maruyama K, Ishii KJ, Barber GN, et al. DNA Damage Sensor MRE11 Recognizes Cytosolic Double-Stranded DNA and Induces Type I Interferon by Regulating STING Trafficking. Proc Natl Acad Sci USA (2013) 110:2969-74. doi: 10.1073/pnas.1222694110

179. Basit A, Cho M-G, Kim E-Y, Kwon D, Kang S-J, Lee J-H. The cGAS/STING/ TBK1/IRF3 Innate Immunity Pathway Maintains Chromosomal Stability Through Regulation of p21 Levels. Exp Mol Med (2020) 52:643-57. doi: 10.1038/s12276-020-0416-y

180. Nguyen HQ, To NH, Zadigue P, Kerbrat S, De La Taille A, Le Gouvello S, et al. Ionizing Radiation-Induced Cellular Senescence Promotes Tissue Fibrosis After Radiotherapy. A Review. Crit Rev Oncol Hematol (2018) 129:13-26. doi: 10.1016/j.critrevonc.2018.06.012

181. Citrin DE, Shankavaram U, Horton JA, Shield W, Zhao S, Asano H, et al. Role of Type Ii Pneumocyte Senescence in Radiation-Induced Lung Fibrosis. J Natl Cancer Inst (2013) 105:1474-84. doi: 10.1093/jnci/djt212

182. Wang L-K, Wu T-J, Hong J-H, Chen F-H, Yu J, Wang C-C. Radiation Induces Pulmonary Fibrosis by Promoting the Fibrogenic Differentiation of Alveolar Stem Cells. Stem Cells Int (2020) 2020:6312053. doi: 10.1155/2020/ 6312053

183. Wang Y, Boerma M, Zhou D. Ionizing Radiation-Induced Endothelial Cell Senescence and Cardiovascular Diseases. Radiat Res (2016) 186:153-61. doi: $10.1667 / R R 14445.1$

184. Philipp J, Le Gleut R, von Toerne C, Subedi P, Azimzadeh O, Atkinson MJ, et al. Radiation Response of Human Cardiac Endothelial Cells Reveals a Central Role of the Cgas-STING Pathway in the Development of Inflammation. Proteomes (2020) 8(4):30. doi: 10.3390/proteomes8040030

185. Zhang Y, Chen W, Wang Y. STING Is an Essential Regulator of Heart Inflammation and Fibrosis in Mice With Pathological Cardiac Hypertrophy Via Endoplasmic Reticulum (ER) Stress. Biomed Pharmacother (2020) 125:110022. doi: 10.1016/j.biopha.2020.110022

186. Liu Y, Jesus AA, Marrero B, Yang D, Ramsey SE, Sanchez GAM, et al. Activated STING in a Vascular and Pulmonary Syndrome. $N$ Engl J Med (2014) 371:507-18. doi: 10.1056/NEJMoa1312625

187. Campisi M, Sundararaman SK, Shelton SE, Knelson EH, Mahadevan NR, Yoshida R, et al. Tumor-Derived Cgamp Regulates Activation of the Vasculature. Front Immunol (2020) 11:2090. doi: 10.3389/fimmu. 2020.02090

Conflict of Interest: The authors declare that the research was conducted in the absence of any commercial or financial relationships that could be construed as a potential conflict of interest.

Copyright $\odot 2021$ Constanzo, Faget, Ursino, Badie and Pouget. This is an open-access article distributed under the terms of the Creative Commons Attribution License (CC BY). The use, distribution or reproduction in other forums is permitted, provided the original author(s) and the copyright owner(s) are credited and that the original publication in this journal is cited, in accordance with accepted academic practice. No use, distribution or reproduction is permitted which does not comply with these terms. 